\title{
Hydrogen Bonding in Transient Bifunctional Hypervalent Radicals by Neutralization-Reionization Mass Spectrometry
}

\author{
Scott A. Shaffer and František Tureček \\ Department of Chemistry, University of Washington, Seattle, Washington, USA
}

\begin{abstract}
Neutralization-reionization mass spectrometry is used to generate hypervalent 9-N-4 (ammonium) and 9-O-3 (oxonium) radicals derived from protonated $\alpha$, $\omega$-bis-(dimethylamino)alkanes and $\alpha, \omega$-dimethoxyalkanes, which exist as cyclic hydrogen-bonded structures in the gas phase. Collisional neutralization with dimethyl disulfide, trimethylamine, and xenon of the hydrogen-bonded onium cations followed by reionization with oxygen results in complete dissociation. Bond cleavages at the hypervalent nitrogen atoms are found to follow the order $\mathrm{CH}_{2}-\mathrm{N}>\mathrm{CH}_{3}-\mathrm{N}>\mathrm{N}-\mathrm{H}$, which differs from that in the monofunctional hydrogen-n-heptyldimethylammonium radical, which gives $\mathrm{CH}_{2}-\mathrm{N}>\mathrm{N}-\mathrm{H}>\mathrm{CH}_{3}-\mathrm{N}$. No overall stabilization through hydrogen bonding of the bifunctional hypervalent ammonium and oxonium radicals is observed. Subtle effects of ring size are found that tend to stabilize large ring structures and are attributed to intramolecular hydrogen bonding. (/ $\mathrm{Am}$ Soc Mass Spectrom 1995, 6, 1004-1018)
\end{abstract}

$\mathrm{T}$ The effects of hydrogen bonding have been of both theoretical [1-4] and experimental interest [5-9]. Bifunctional neutral molecules that have a proton donor group $\left(\mathrm{OH}, \mathrm{NH}_{2}\right)$ in spatial proximity with an electron-rich proton acceptor group (OR, $N_{2}$ ) typically develop a stabilizing interaction because of the formation of an intramolecular hydrogen bond [10]. Intramolecular hydrogen bonding in neutral molecules has been studied extensively in both solution and the gas phase [11-14]. The latter is an especially good medium for study of the hydrogen bonding phenomena because of the absence of solvent effects [15]. Stabilization through hydrogen bonding in neutral molecules typically amounts to $15-20 \mathrm{~kJ} \mathrm{~mol}^{-1}$, which depends on the properties of the proton donor and acceptor groups [16].

Strong intramolecular hydrogen bonding occurs in protonated $\alpha, \omega$-bifunctional alkane cations as revealed by gas-phase basicity studies $[8,9,17]$. This is borne out by proton transfer equilibrium studies [17] that gave larger proton affinity $(\mathrm{PA})$ values measured for protonated bifunctional ions as compared to monofunctional species of comparable polarizability. In addition, large negative entropy changes $\left(\Delta S^{\circ}\right)$ accompany protonation of these species and thus lead to unambiguous assignment of their cyclic structures [9].

Address reprint requests to Professor František Tureček, Department of Chemistry, University of Washington, Box 351700, Seattle, WA 98195-1700.
This phenomenon has been noted in many $\alpha, \omega$-bifunctional alkanes, which include diamines, diethers, and diols, as well as in alkanes that contain two different functional groups (e.g., amino alcohols) [17].

The extent of hydrogen bonding, defined as the hydrogen bonding stabilization energy $\left(\Delta H_{\text {stat }}\right)$, can be estimated from the difference of PA values between a bifunctional species and a monofunctional species of comparable polarizability. For example, in a series of diaminoalkanes Aue et al. [8] estimated $\Delta H_{\text {stab }}$ as $\sim 41,65,85,76$, and $79 \mathrm{~kJ} \mathrm{~mol}^{-1}$ for 1,2-diaminoethane, 1,3-diaminopropane, 1,4-diaminobutane, 1,5-diaminopentane, and 1,6-diaminohexane, respectively. Chemical modeling of cyclic systems [18] was used to explain the preceding values where the protonated 1,4-diaminobutane ion exhibited the least ring strain and hence the largest $\Delta H_{\text {stab }}$ value [8].

Much less is known about hydrogen bonding in open-shell species, such as cation-radicals and radicals [19]. Morton and co-workers [20, 21] proposed that intramolecular hydrogen bonding in 2-methoxyethanol is retained in its corresponding cation-radical and influences its unimolecular dissociations; the latter presumably involve a proton-bridged intermediate. In contrast, ab initio studies of the 1,2-ethanediol cationradical predicted fast rearrangement by hydrogen transfer in the hydrogen-bonded structure [22, 23], which implies no stabilization through hydrogen bonding. The mechanisms of collision-activated dissociation (CAD) in 1,2-ethanediol and 2-methoxyethanol 
cation-radicals were studied by Cao et al. [24], who also concluded that the ions were not stabilized by hydrogen bonding.

An interesting possibility for the study of intramolecular hydrogen bonding in radicals is provided by fast neutralization of protonated $\alpha, \omega$-bifunctional alkanes via neutralization-reionization (NR) mass spectrometry [25-33]. Neutralization by collisional electron transfer of ions with kiloelectronvolt kinetic energies occurs on a $<10^{-14}$-s time scale, such that the neutral species is formed with the geometry of the precursor ion. Neutralization of protonated diamines and diethers, as presented in this study, produces hypervalent radicals of the 9-N-4 (ammonium) and 9-O-3 (oxonium) type, whose initial geometries correspond to those of the hydrogen-bonded cations. For the X-N-L nomenclature of hypercoordinated species, see ref 34. Previous theoretical [35] and experimental [36] studies of $\mathrm{NH}_{3} \cdots \mathrm{NH}_{4}$ hypervalent radicals indicated significant stabilization against $\mathrm{NH}_{+}$that was attributed to hydrogen bonding.

In the present study we investigate the effects of intramolecular hydrogen bonding on the stability and dissociations of larger organic hypervalent radicals prepared by neutralization of protonated bis-(dimethylamino)alkanes 1-4 and protonated bis-(methoxy)alkanes 5 and 6 . Compounds 1-6 are strong organic gas-phase bases, which makes them particularly well suited for the study of hydrogen bonding effects. The PA values are 1004, 1017, 1029, 1025, 853, and $928 \mathrm{~kJ}$ mol $^{-1}$, respectively, for compounds 1-6 [17, 37, 38]. Although accurate estimates of $\Delta H_{\text {stab }}$ for these compounds are hampered by rather sparse PA data for monofunctional compounds with comparable alkyl groups, the PA data suggest relative $\Delta H_{\text {stab }}$ values similar to those discussed for the diaminoalkanes [8].

Gas-phase protonation of 1-6 by isobutane chemical ionization (PA(2-methylpropene) $=802 \mathrm{~kJ} \mathrm{~mol}^{-1}$ [38]) results in the formation of cyclic cations $7^{+}-12^{+}$, respectively. Neutralization of ions $7^{+}-12^{+}$by fast collisions with dimethyl disulfide results in the formation of hypervalent radicals whose NR mass spectra are presented. CAD mass spectra of ions $1^{+-}-6^{+\cdot}$ (which correspond to reionized molecules) and $7^{+}-12^{+}$(which correspond to reionized radicals) are presented for comparison. Deuterium-labeled ions $3 a^{+}, 9 a^{+}$, and $9 b^{+}$ are used to elucidate dissociation pathways for the hypervalent radical derived from $9^{+}$. To compare the behavior of bifunctional hypervalent radicals with respect to hydrogen bonding and interactions of the functional groups, we also investigated dissociations of hypervalent radicals derived from $\mathrm{C}_{4} \mathrm{H}_{4}^{+}$-protonated 1-( $N, N$-dimethylamino)heptane $\left(13^{+}\right)$and its deuterium-labeled isotopomers $N$-methyl- $N$-(methyl$d_{3}$ )aminoheptane $\left(\mathbf{1 3} \mathbf{a}^{+}\right)$and $N, N$-dimethylaminoheptane-1,1- $d_{2}\left(13 b^{+}\right)$. As with the other radicals studied, radicals $13-13 b^{\circ}$ also were generated by neutralization with dimethyl disulfide.
(1) $\left(\mathrm{CH}_{3}\right)_{2} \mathrm{~N}-\left(\mathrm{CH}_{2}\right)_{2}-\mathrm{N}\left(\mathrm{CH}_{3}\right)_{2}$

(2) $\left(\mathrm{CH}_{3}\right)_{2} \mathrm{~N}-\left(\mathrm{CH}_{2}\right)_{3}-\mathrm{N}\left(\mathrm{CH}_{3}\right)_{2}$

(3) $\left(\mathrm{CH}_{3}\right)_{2} \mathrm{~N}-\left(\mathrm{CH}_{2}\right)_{4}-\mathrm{N}\left(\mathrm{CH}_{3}\right)_{2}$

(3a) $\left(\mathrm{CH}_{3}\right)_{2} \mathrm{~N}-\mathrm{CD}_{2}\left(\mathrm{CH}_{2}\right)_{2} \mathrm{CD}_{2}-\mathrm{N}\left(\mathrm{CH}_{3}\right)_{2}$

(4) $\left(\mathrm{CH}_{3}\right)_{2} \mathrm{~N}-\left(\mathrm{CH}_{2}\right)_{6}-\mathrm{N}\left(\mathrm{CH}_{3}\right)_{2}$

(5) $\mathrm{CH}_{3} \mathrm{O}-\left(\mathrm{CH}_{2}\right)_{2}-\mathrm{OCH}_{3}$

(6) $\mathrm{CH}_{3} \mathrm{O}-\left(\mathrm{CH}_{2}\right)_{4}-\mathrm{OCH}_{3}$

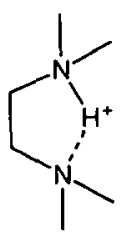

$\left(7^{+}\right)$

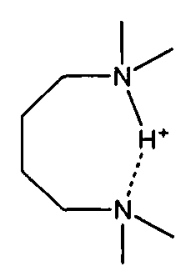

$\left(9^{+}\right)$<smiles>[2H]C1(C)CCC([2H])([2H])[N+](C)(C)[PH2+]N1C</smiles>

$\left(9 a^{+}\right)$

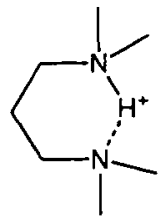

$\left(\mathbf{8}^{+}\right)$<smiles></smiles>

$\left(9 b^{+}\right)$<smiles>CN1[CH+][N+](C)(C)CCCCCC1</smiles>

$\left(10^{+}\right)$<smiles>CO[C]1OCC[In]1</smiles>

$\left(11^{+}\right)$

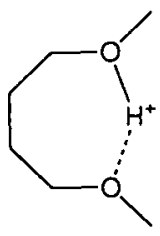

$\left(12^{+}\right)$<smiles>CCCCCCC[N+](C)(C)C</smiles>

$\left(13^{+}\right)$

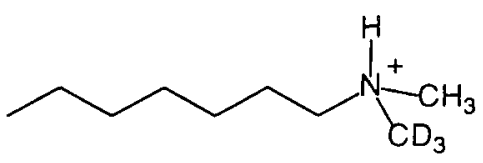

$\left(13 a^{+}\right)$<smiles>[2H]C([2H])(CCCCCC)[N+](C)C</smiles>

$\left(13 b^{+}\right)$

Structure 13 


\section{Experimental}

\section{Neutralization-Reionization Mensurements}

NR (abridged notation for ${ }^{+} \mathrm{NR}^{+}$, or positive ions neutralized followed by reionization to positive ions) mass spectra were measured on the tandem quadrupole acceleration-deceleration (QADQ) mass spectrometer described previously [39]. Samples were introduced into the ion source via a glass probe maintained at room temperature. The sample intake was regulated by a Teflon valve to achieve pressures in the range of $8 \times 10^{-6}$ to $2 \times 10^{-5}$ torr as read on an ionization gauge located outside the ion source. Cation precursor ions were generated by gas-phase protonation of the corresponding diamines (1-4), N,Ndimethylaminoheptanes, and diethers (5 and 6) with $\mathrm{C}_{4} \mathrm{H}_{9}^{+}$[from isobutane (Matheson, East Rutherford, $\mathrm{NJ}), 99.5 \%$ ] generated by chemical ionization $(\mathrm{CI})$ in a tight ion source of our design. $\mathrm{Cl}$ conditions were as follows: emission current, $1 \mathrm{~mA}$; electron energy, 100 $\mathrm{eV}$; ion source temperature, $165-190{ }^{\circ} \mathrm{C}$ (dependent on particular experiment); isobutane pressure, $-2 \times 10^{-t}$ torr as read on the ionization gauge located outside the ion source. The reagent gas pressure and ion source potentials were adjusted to optimize protonation and minimize electron ionization such as to obtain the highest possible ion abundance ratios $[\mathrm{M}+\mathrm{H}]^{+} /\left[\mathrm{M}^{\prime \prime}\right]$. Cation $\mathbf{9} \mathbf{b}^{+}$was prepared by deuteronation with $\mathrm{ND}_{4}{ }^{\prime}$ and $\mathrm{C}_{4} \mathrm{D}_{4}^{+}$generated by $\mathrm{CI}$ of $\mathrm{ND}_{3}$ (Cambridge Isotope Laboratories, Woburn, $\mathrm{MA} ; 99 \mathrm{C} ; \mathrm{D})$ and $\left(\mathrm{CD}_{3}\right)_{3} \mathrm{CD}$ (MSD Isotopes, Pointe Claire, Quebec, Canada; $98 \%$ D), respectively. The ion source and gas inlet walls were conditioned with $\mathrm{D}_{2} \mathrm{O}$ (Cambridge Isotopes; $99.9 \% \mathrm{D})$ at $2 \times 10^{-5}$ torr for $-1 \mathrm{~h}$ prior to the labeled experiments. Cation-radical precursor ion $\mathbf{1}^{*}$ was generated by electron impact (EI) ionization of the corresponding 1,2-bis-(dimethylaminolethane. EI ion source conditions were as follows: electron energy, $70 \mathrm{eV}$; emission current, $0.5 \mathrm{~mA}$; ion source temperature $185{ }^{\circ} \mathrm{C}$. In all cases the ions were passed through a quadrupole mass filter operated in the radiofrequency-only mode, accelerated to $-8130-\mathrm{eV}$ kinetic energy $( \pm 30 \mathrm{eV}$ dependent on the particular experiment), and neutralized by collisions with gaseous dimethyl disulfide (Aldrich, Chemical Co., Milwaukee, WI; 99\%), trimethylamine (Matheson, $99.5 \%$ ), or xenon (Matheson, $99.9 \%$ ) in a differentially pumped collisional cell at a pressure such as to achieve $70 \%$ transmittance of the incident ion beam. The remaining ions were reflected electrostatically and the neutrals were reionized to cations by collisions with oxygen in another differentially pumped cell at a pressure such as to achieve $70 \%$ transmittance of the precursor ion beam. The intermediate neutral lifetimes were in the 4.8-6.6- $\mu$ s range for precursor ions of $m /=$ 91-173. The positive ions then were decelerated by an electrostatic lens, energy filtered, and mass analyzed by a quadrupole mass filter (MS-II) that was scanned in link with the deceleration voltage [39]. The reported spectra were recorded on a PC-based data acquisition program [40] and averaged over $20-50$ repetitive scans obtained at scan rates of $1 \mathrm{~s}$ ( 75 data points) per mass unit.

Operation of the first quadrupole mass filter in the radiofrequency-only mode significantly increases the amount of precursor ions available for neutralization. However, mass analysis by linked scanning of the deceleration voltage and the MS-Il quadrupole mass filter, but without prior mass selection of the precursor ion, may result in interferences due to formation of the same fragment by the two precursor ions at adjacent mass-to-charge ratio values (to the desired precursor ion). For example, fragmentations of precursor ions (or neutrals) of 8130-eV kinetic energy, $m / z 146$ (the desired precursor) to 71 and $m /=145$ (adjacent precursor) to 71 from $9 \mathrm{~b}^{r}$, yield the $m / z 71$ fragments with kinetic energies equal to 3954 and $3981 \mathrm{eV}$, respectively. Whereas these peak maxima that differ by 27 $\mathrm{eV}$ are resolved by the energy filter lens $(\triangle E=45 \mathrm{eV}$ full width at half maximum [39]), energy spread due to kinetic energy release in the fragmentation can cause peak broadening and overlap. In practice, contamination from adjacent precursor ions is minimized by optimization of the $\mathrm{Cl}$ source conditions to obtain the highest possible ion abundance ratios for $[\mathrm{M}+$ $\mathrm{H}]^{+} /\left[\mathrm{M}^{+}\right]$.

Other relevant features of the QADQ mass spectrometer that affect the overall appearance of the obtained mass spectrum are the deflector and energy filter potentials located after the reionization cell prior to the MS-II quadrupole [39]. The settings of the deflectors and energy filter can affect the transmission of low mass fragments. For example, when the NR mass spectrum of $\mathbf{9 b}$ ' (deuteronated by $\boldsymbol{d}_{3}$-ammonia, Figure $2 b)$ was measured with different energy filter and deflector settings nearly two years after the other NR spectra were measured, differences in the relative abundances of low mass fragments were observed. However, when the NR spectrum of $9 \mathbf{b}^{+}$(deuteronated by $d_{10}$-isobutane; spectrum not shown) was taken with deflector and energy filter settings similar to those of the other NR spectra presented, this low mass discrimination did not occur.

\section{Collision-Actizated Dissociation Measurements}

CAD mass spectra of ions at 4-keV kinetic energy were taken on a Kratos (Kratos Analytical, Ramsey, NJ) Profile HV-4 double-focusing mass spectrometer that had a forward (E precedes B) geometry. The ions were collided with $\mathrm{O}_{2}$ at $70 \%$ precursor beam transmittance in the first field-free region of the mass spectrometer furnished with a home-built collision cell. The spectra were obtained by scanning the $E$ and $B$ sectors while keeping the $\mathrm{B} / \mathrm{E}$ ratio constant. Product ion mass resolution was $>300$. An average of 8-12 repetitive scans 
were taken for each spectrum at a rate of $30 \mathrm{~s}$ per decade.

\section{Materials}

1,2-Bis-(dimethylamino)ethane (1) (Aldrich; 99\%), 1,3-bis-(dimethylamino)propane (2) (Aldrich; 99\%), 1,-bis-(dimethylamino)butane (3) (Aldrich; 98\%), 1,6bis-(dimethylamino)hexane (4) (Aldrich; $99 \%$ ), and 1,2bis-(methoxy)ethane (5) (Aldrich; 99.9r;) were used as received.

1,4-Bis-(dimethylamino)butane-1,1,4,4-1 + (3a), $N, N$-dimethylaminoheptane, and $N$-methyl-N(methyl- $d_{3}$ )aminoheptane were synthesized by reduction with $\mathrm{LiAlD}_{4}$ or $\mathrm{LiAlH}_{4}$ of the corresponding amides in accordance with standard procedures described previously [41]. 70-eV EI mass spectra (not reported previously) are as follows [mass-to-charge ratio and percent relative intensity (in parentheses)]: 1,4-Bis-(dimethylamino)butane-1,1,4,4-14: $149(0.6), 148$ $\left(\mathrm{M}^{+}, 6.8\right), 133(1.3), 104(2.3), 102(2.3), 101(2.6), 88$ (5.1), $87(2.6), 86(1.2), 85(1.6), 76(1.1), 74(5.1), 73(1.8)$, $72(18.6), 71(3.2), 61(4.7), 60(100), 59(7.1), 58(2.0), 57$ (3.0), $47(0.9), 46(22.0), 45(8.1), 4+(10.0), 43(11.5), 42$ (13.8), $41(5.3), 40(3.3), 35$ (1.7).

$N, N$-dimethylaminoheptane: $14+(0.5), 143\left(\mathrm{M}^{*}, 4.8\right)$, $142(0.5), 11+(0.4), 84(0.9), 72(2.5), 71(2.6), 70(1.1), 69$ $(0.5), 59(4.0), 58(100), 57(2.0), 56(1.6), 55(1.8), 53$ $(0.3), 46(0.3), 45(1.0), 44(2.2), 43(2.5), 42(6.4), 41(3.4)$, $40(0.6), 39(1.1)$.

$N$-methyl-N-(methyl-t $t_{3}$ )aminoheptane: $147(0.3), 146$ $\left(\mathrm{M}^{+}, 3.9\right), 145(0.4), 87(0.4), 75(0.3), 74(0.4), 72(0.5)$, $71(0.5), 62(3.6), 61(100), 60(1.1), 59(0.4), 57(0.5), 56$ $(0.4), 55(1.1), 48(1.1), 47(1.2), 46(0.9), 45(1.6), 44(2.2)$, $43(1.7), 42(2.8), 41(2.6), 40(0.6), 39(0.9)$.

$N, N$-dimethylaminoheptane-1,1-d $d_{2}$ was prepared by $\mathrm{LiAlD}_{4}$ reduction of $N, N$-dimethylheptanamide in tetrahydrofuran and distilled in vacuo, b.p. $62{ }^{\circ} \mathrm{C}$ (24 torr). Thin-layer chromatography (TLC) $\left(\mathrm{CHCl}_{3} / \mathrm{CH}_{3} \mathrm{OH}\right.$, normal phase) gave one spot by $\mathrm{I}_{2}$ vapor $\left(R_{f} \sim 0.35\right) .200-\mathrm{MHz}{ }^{1} \mathrm{H}$ NMR $\left(\mathrm{CDCl}_{3}\right): 0.88$ $(t, 3 \mathrm{H}), 1.28(\mathrm{~m})+1.45(\mathrm{~m})(10 \mathrm{H}), 2.2(\mathrm{~s}, 6 \mathrm{H})$.

1,4-Dimethoxybutanc (6). Dimethyl sulfate $[60.5 \mathrm{~g}$ $(0.480 \mathrm{~mol})$; Aldrich; $99 \%$ ] was added dropwise to a stirred solution of $20 \mathrm{~g}(0.222-\mathrm{mol}) 1,4$-butanediol (Aldrich; $99 \%$ ) in $-200 \mathrm{~mL}$ of aqueous $2.4-\mathrm{M} \mathrm{NaOH}$ at room temperature and then refluxed for $2 \mathrm{~h}$. The reaction mixture was cooled and the product was extracted with $4 \times\left(20-\mathrm{g} \mathrm{K}_{2} \mathrm{CO}_{3}+50-\mathrm{mL}\right.$ ether $)$. Microdistillation at normal pressure yielded $\sim 5 \mathrm{~g}(42$ mmol, $19 \%$ yield) of a clear liquid of b.p. $90-92{ }^{\circ} \mathrm{C}$. The 70-eV EI mass spectrum ( $11 \mathrm{l} / \mathrm{z}$, mass-to-charge ratio and percent relative intensity (in parentheses)]: $119(0.9), 118\left(\mathrm{M}^{+}, 2.8\right), 117(2.0), 116(0.6), 105(0.7)$, $104(6.1), 103(96), 102(0.3), 101(0.5), 92(0.3), 91(0.4)$, $90(1.0), 89(0.4), 88(5.5), 87(8.2), 86(35), 85(18), 84$ $(0.4), 75(1.3), 74(0.5), 73(0.6), 72(3.3), 71(33), 70(0.6)$, $69(1.0), 68(0.2), 67(0.3), 61(0.3), 60(0.5), 59(7.0), 58$
(100), $57(2.9), 56(6.0), 55(7.5), 54(0.6), 53(2.5), 52$ $(0.2), 51(0.3), 50(0.2), 49(0.5), 47(0.7), 46(2.0), 45(85)$, $44(1.2), 43(16), 42(4.0), 41(9.7), 40(1.4), 39(6.1)$.

\section{Results}

\section{Ion Dissociations}

Because the neutral species that result from collisional neutralization are reionized prior to detection, the NR spectrum represents a convolution of neutral and ion processes. Although we did not intend to study the mechanistic details of ion dissociations, the significant products of ion dissociations needed to be identified as signatures for the neutral intermediates. Thus the dissociations of cation-radicals $1^{*}-6^{\prime}$ (which correspond to reionized molecules) and cations $7^{+}-12^{+}$(which correspond to reionized radicals) were investigated through their collision-induced dissociation (CAD) mass spectra, in conjunction with the electron impact (EI) mass spectra of the diamines and diethers.

CAD of diamine cation-radicals $1^{+\cdot}-4^{+\cdot}$ yields fragment ion spectra that differ significantly in appearance (Table 1). The major dissociation pathways for $1^{\prime \prime}-4$ " are seemingly unique to the alkyl chain length between amine moieties. The major dissociation pathway for the 1,2-bis-(dimethylamino)ethane cation-radical $\left(1^{*}\right)$ is $\alpha$-cleavage that gives rise to $\mathrm{CH}_{2}=\mathrm{N}\left(\mathrm{CH}_{3}\right)_{2}^{*}$ $[41,42]$ as the base peak of the CAD spectrum (Table 1). A similar pattern is observed in the 70-eV EI mass spectrum of 1 , which in addition to $m / z 58$ shows fragment ions at $m /=72,71$, and 42 [43]. The molecular ion of 1 is weak in the EI mass spectrum $(4 \%$ of base peak $m /=58$ ). CAD of the 1,3-bis-(dimethylamino)propane cation-radical $\left(2^{+\cdot}\right)$ shows a dominant peak at $m /=85$ due to elimination of dimethylamine (Table 1). This fragment ion is much less abundant in the 70-eV EI mass spectrum of 2 (22\% of the base peak $m /=58$ [43]). This difference is possibly due to the fact that the relative intensity of a rearrangement ion in the CAD spectrum depends on the ion internal energy and may be promoted in a fraction of low energy ions produced by CAD $[44,45]$. Different time scales of these dissociations also may have a substantial effect. Nondissociating $2^{+\cdot}$ sampled for CAD have longer lifetimes than the ions that dissociate in the ion source, and so the former may have undergone a $C \rightarrow N$ hydrogen transfer rearrangement to form a distonic structure, which would be prone to elimination of dimethylamine. Whichever scenario is the case, it appears that the dissociations of $2^{+\cdot}$ formed by reionization in the NR process (vide infra) are better approximated by the EI mass spectrum of 2 than by its CAD spectrum. Unfortunately, the very low relative abundance of the molecular ion $2^{+\cdot}$ [43] did not permit its NR spectrum to be obtained for direct comparison.

Interestingly, CAD of the 1,4-bis-(dimethylamino)butane cation-radical $\left(3^{+*}\right)$ (Table 1$)$ proceeds 
Table 1. $\mathrm{CADHO}_{2}, 70 \%$ transmittance) mass spectra of $\alpha$, $\omega$-dimethylaminolalkanes $1^{+}-4^{+*}$ and $\alpha, \omega$-(dimethoxy)alkanes $5^{+\cdot}$ and $6^{+\cdot *}$

\begin{tabular}{|c|c|c|c|c|c|c|c|}
\hline$m / z$ & $1^{+}$ & $2^{+*}$ & 3 & $3 a^{\prime}$ & $4^{+}$ & 5 & $6^{+1}$ \\
\hline 172 & & & & & $M^{*}$ & & \\
\hline 171 & & & & & $(18)$ & & \\
\hline 158 & & & & & 0.2 & & \\
\hline 157 & & & & & 2.2 & & \\
\hline 148 & & & & $M \cdots$ & & & \\
\hline 147 & & & & $(9.6)$ & & & \\
\hline 144 & & & $\mathrm{M}^{+\cdot}$ & & & & \\
\hline 143 & & & $(1.4)$ & & & & \\
\hline 134 & & & & 2.5 & & & \\
\hline 133 & & & & 29 & & & \\
\hline 132 & & & & 0.5 & & & \\
\hline 130 & & $M^{*}$ & 2.6 & & 0.1 & & \\
\hline 129 & & $(0.2)$ & 30 & & 4.6 & & \\
\hline 128 & & & & & 45 & & \\
\hline 127 & & & & & 23 & & \\
\hline 126 & & & & & 2.2 & & \\
\hline 118 & & & & & & & $M^{\prime}$ \\
\hline 117 & & & & & & & (15) \\
\hline 116 & $\mathrm{M}^{+\cdot}$ & & & & & & \\
\hline 115 & $(0.9)$ & & & & 0.4 & & \\
\hline 114 & & & & & 3.9 & & \\
\hline 113 & & & & & 0.1 & & \\
\hline 112 & & & & & 0.5 & & \\
\hline 110 & & & & & 0.1 & & \\
\hline 106 & & & & 0.4 & & & \\
\hline 105 & & & & 6.3 & & & \\
\hline 104 & & & & 15 & & & 1.5 \\
\hline 103 & & & & 2.4 & & & 36 \\
\hline 102 & & & 0.4 & 5.8 & & & 0.1 \\
\hline 101 & & & 6.3 & 1.6 & 0.2 & & \\
\hline 100 & & & 13 & 0.1 & 0.3 & & \\
\hline 99 & 0.1 & & 6.5 & 0.1 & & & \\
\hline 98 & & & 2.9 & & 0.2 & & \\
\hline 97 & & & & & 0.1 & & \\
\hline 96 & & & 0.1 & & 0.1 & & \\
\hline 90 & & & & 0.1 & & $M^{*}$ & 0.1 \\
\hline 89 & & & & 0.1 & & $(0.1)$ & 0.1 \\
\hline 88 & & & & 1.2 & & & 3.0 \\
\hline 87 & & 0.2 & & 0.7 & & & 11 \\
\hline 86 & & 7.6 & 0.4 & 0.7 & 0.4 & & 13 \\
\hline 85 & & 83 & 0.9 & 0.6 & 0.2 & & 11 \\
\hline 84 & & 0.9 & 2.4 & 0.1 & 2.3 & & 0.1 \\
\hline 83 & & & 0.2 & 0.1 & & & \\
\hline 82 & & & 0.3 & & 0.1 & & \\
\hline 81 & & & & & 0.2 & & \\
\hline 77 & & & & 0.2 & & & \\
\hline 76 & & & & 4.6 & & & \\
\hline 75 & & & & 0.6 & & & \\
\hline 74 & & & 0.2 & 9.2 & & & 0.1 \\
\hline 73 & & & 3.9 & 0.5 & & & \\
\hline 72 & 1.6 & 0.4 & 8.0 & 3.3 & 0.2 & 0.2 & 0.4 \\
\hline 71 & 1.4 & 0.9 & 5.2 & 0.3 & 0.6 & & 2.3 \\
\hline
\end{tabular}




\begin{tabular}{|c|c|c|c|c|c|c|c|}
\hline$m / z$ & $1^{\prime}$ & 2 & $3 \cdots$ & $3 a^{\prime}$ & $4^{\prime \prime}$ & $5^{\prime}$ & 6 \\
\hline 70 & 0.8 & 0.8 & 0.5 & 0.1 & 0.4 & & \\
\hline 69 & & & & 0.1 & & & 0.2 \\
\hline 68 & & & 0.2 & & 0.1 & & \\
\hline 61 & & & & 0.4 & & 1.7 & \\
\hline 60 & & & & 8.1 & & 47 & \\
\hline 59 & 2.7 & 0.2 & 0.4 & 0.5 & 0.4 & 1.6 & 0.4 \\
\hline 58 & 90.5 & 3.6 & 9.6 & 0.3 & 8.4 & 19 & 8.9 \\
\hline 57 & 1.2 & 0.4 & 0.4 & 0.4 & 0.2 & & 0.2 \\
\hline 56 & 0.4 & 0.2 & 0.5 & 0.1 & 0.2 & & 0.8 \\
\hline 55 & & & 0.4 & 0.1 & 0.2 & & 1.7 \\
\hline 54 & & & & & & & 0.1 \\
\hline 53 & & & & & & & 0.5 \\
\hline 47 & & & & 0.2 & & & \\
\hline 46 & & & 0.1 & 1.5 & 0.2 & 0.4 & \\
\hline 45 & & 0.2 & 1.5 & 0.5 & 0.4 & 24 & 4.5 \\
\hline 44 & 0.2 & 0.5 & 0.8 & 0.3 & 0.6 & 0.4 & 0.1 \\
\hline 43 & 0.2 & 0.2 & 0.3 & 0.5 & 0.1 & 0.7 & 0.8 \\
\hline 42 & 0.9 & 0.6 & 0.8 & 0.3 & 0.4 & 0.2 & 0.7 \\
\hline 41 & & 0.2 & 0.2 & & 0.1 & & 1.2 \\
\hline 40 & & & & & & & 0.1 \\
\hline 39 & & & & & & & 0.7 \\
\hline 33 & & & & & & 0.1 & 0.1 \\
\hline 31 & & & & & & 1.0 & \\
\hline 30 & & & & & & 0.3 & 0.2 \\
\hline 29 & & & & & & 2.1 & \\
\hline 28 & & & & & & 0.5 & 0.1 \\
\hline 27 & & & & & & 0.2 & \\
\hline
\end{tabular}

a Values are percent relative to the sum of ion intensities measured as integrated peak areas. lons $1 \cdots 4$ " were not monitored below $m / 240$.

by loss of methyl to give a dominant ion at $m /=129$ (base peak), whereas products formally due to $\mathrm{CH}_{2}-\mathrm{N}, \alpha$-cleavage, and $\beta$-cleavage at $m / z 100,58$, and 72 , respectively, are less abundant. Product ion abundances due to $\mathrm{N}-\mathrm{CH}_{3}$ and $\mathrm{N}-\mathrm{CH}_{2}$ bond cleavages in $3^{+\cdot}$ appear in a near statistical ratio: 2:0.9 for ions at $m / z 129$ and 100 , respectively. By contrast, the 70-eV EI mass spectrum of 3 shows a dominant $\mathrm{CH}_{2}=\mathrm{N}\left(\mathrm{CH}_{3}\right)_{2}^{+}$ion, whereas the ions at $\mathrm{m} / \mathrm{z} 129$ and 100 are less abundant $(4$ and $3 \%$ of $m / z 58$, respectively [43]). These differences likely reflect different excitations in $\mathrm{EI}$ and $\mathrm{CAD}$, the latter reflecting a higher fraction of low energy processes. It should be noted that the loss of an $N$-methyl group from $3^{+*}$ (and $3 \mathbf{a}^{+\cdot}$ ) is likely to be accompanied by a rearrangement, because a direct loss would produce an unstable nitrenium ion [46]. The CAD spectrum of deuteriumlabeled $\mathbf{3 a}^{+\cdot}$ (Table 1 ) shows clean mass shifts from $m / z 129$ to 133 (base peak), $m / z 100$ to $104, m / z 58$ to 60 , and $m / z 72$ to 74 for $\mathrm{N}-\mathrm{CH}_{3}, \mathrm{~N}-\mathrm{CH}_{2}, \alpha-$ cleavage, and $\beta$-cleavage products, respectively, which indicates that the $\alpha$-deuterium atoms do not migrate onto the neutral fragments being eliminated. In analogy with $3^{+\cdot}$ that forms $m / z 58$, the $70-\mathrm{eV}$ EI spectrum of 3a (see Experimental) yields a dominant $\mathrm{CD}_{2}=\mathrm{N}\left(\mathrm{CH}_{3}\right)_{2}^{+}$ion shifted to $\mathrm{m} / \mathrm{z} 60$ [41].

The CAD spectrum of the 1,6-bis-(dimethylamino)hexane cation-radical $\left(4^{+\cdot}\right.$ ) (Table 1) suggests a competition between $\mathrm{CH}_{2}-\mathrm{N}$ cleavage (base peak, $m / z 128)$ and the loss of dimethylamine $(m / z 127)$. Other dissociations such as loss of methyl $(\mathrm{m} / \approx 157)$ and $\alpha$-cleavage products $(\mathrm{m} / z 58)$ are less important for $4^{+*}$. By contrast, the $70-\mathrm{eV}$ EI mass spectrum of 4 gives the $\mathrm{CH}_{2}=\mathrm{N}\left(\mathrm{CH}_{3}\right)_{2}^{+}$ion as the base peak; ions at $m / z 128$ and 127 are less abundant ( 10 and $4 \%$ of the base peak, respectively [43]).

As discussed for the diamines, the CAD spectra of diether cation-radicals $5^{+\cdot}$ and $6^{+\cdot}$ also differ significantly in appearance both from themselves (Table 1) and from their corresponding 70-eV EI spectra [43]. The CAD spectrum of the 1,2-bis-(methoxy)ethane cation-radical $5^{+\cdot}$ shows competitive losses of formaldehyde (base peak, $m / z 60)$ and methanol $(m / z$ 58 ), and the formation of the oxenium ion $\mathrm{CH}_{2}=\mathrm{OCH}_{3}^{+}(m / z 45)$ due to $\alpha$-cleavage. By contrast, the $\alpha$-cleavage product at $m / z 45$ dominates the $70-\mathrm{eV}$ EI spectrum of 5 ; losses of formaldehyde $(\mathrm{m} / \mathrm{z}$ $60)$ and methanol $(m / z 58)$ are less abundant (14 and 
$7 \%$ of the base peak, respectively) [43]. The CAD spectrum of the 1,4-bis-(methoxy)butane cation-radical $\left(6^{+}\right)$shows a dominant loss of methyl radical $(\mathrm{m} / \mathrm{z}$ 103 , base peak), an analogous fragmentation to that observed for diamine $3^{+\cdot}$ (Table 1 ). Other dissociations of $6^{+\cdot}$ formally due to the loss of formaldehyde $(\mathrm{m} / \mathrm{z}$ 88 ), methoxy radical $(\mathrm{m} / \mathrm{z} 87)$, and methanol $(\mathrm{m} / \mathrm{z} 86)$ or formation of $\alpha$-cleavage products $(m / z 45)$ are less abundant. The CAD spectrum of $6^{+\cdot}$ also shows a $\mathrm{C}_{3} \mathrm{H}_{6} \mathrm{O}^{+\cdot}$ ion at $m / z 58$ due to rearrangement. The 70 -eV EI spectrum of 6 is dominated by its $\alpha$-cleavage product ( $m / z 45$, base peak), but also surprisingly by the ion due to rearrangement at $\mathrm{m} / \mathrm{z} 58(81 \%$ of the base peak) [43]. Other rearrangement peaks in the EI spectrum of 6 are less abundant $(7,1$, and $1 \%$ of the base peak for ions at $m / z 86,87$, and 88 , respectively) [43].

Cations $7^{+}-10^{+}$, formed by gas-phase protonation of the corresponding diamines 1-4 by isobutane CI, dissociate predominately by loss of dimethylamine as evidenced by the base peaks in their CAD mass spectra (Table 2). In addition, all diamine cations exhibit an abundant formation of the stable immonium ion $\mathrm{H}_{2} \mathrm{C}=\mathrm{N}\left(\mathrm{CH}_{3}\right)_{2}^{+}$at $m / z 58[41,42]$. Cations $7^{+}$and $8^{+}$show a detectable loss of $\mathrm{NH}_{4}(\mathrm{~m} / z 99$ and 113 , respectively), whereas cations $9^{+}$and $10^{+}$prefer a more abundant loss of $\mathrm{CH}_{4}(\mathrm{~m} / z 129$ and 157, respectively) [47]. The peak at $m / z 129$ is shifted to $m / z 133$ in the CAD spectrum of deuterium-labeled $9 a^{+}$, which indicates a clean loss of nondeuterated methane in its dissociation. The CAD spectrum of deuterium-labeled $9 \mathbf{b}^{+}$, prepared by $\mathrm{ND}_{4}^{+} \mathrm{CI}$, is dominated by a clean loss of $\left(\mathrm{CH}_{3}\right)_{2} \mathrm{ND}$ (base peak, $m / z 100$ ), which indicates a direct bond cleavage in its dissociation. The CAD spectrum of deuterium-labeled $9 \mathbf{a}^{+}$, protonated by isobutane $\mathrm{CI}$, also confirms a clean loss of $\left(\mathrm{CH}_{3}\right)_{2} \mathrm{NH}$ (base peak, $\left.\mathrm{m} / \mathrm{z} 104\right)$ and shows relatively clean mass shift for $m / z 58$ to 60 for $\alpha$-cleavage fragment ions.

The CAD spectra of protonated diethers $11^{+}$and $12^{+}$, formed by isobutane $\mathrm{CI}$, show analogous fragmentations as discussed for the protonated diamines (Table 2). The CAD spectra of $\mathbf{1 1}^{+}$and $\mathbf{1 2}^{+}$show a dominant loss of methanol (base peaks) to give fragment ions at $m / z 59$ and 87 , respectively. The CAD spectrum of $1^{+}$shows a detectable loss of $\mathrm{OH}$ radical and methane, as evidenced by ions at $m / z 74$ and 75 , respectively, whereas $12^{+}$gives a slightly more abundant loss of methane $\left(m / z\right.$ 103). CAD of both $\mathbf{1 1}^{+}$and $12^{+}$results in the formation of the $\mathrm{H}_{2} \mathrm{C}=\mathrm{O}^{+} \mathrm{CH}_{3}$ oxenium ion at $m / z 45$.

\section{Monofunctional Ammonium Radicals}

Neutralization with $\mathrm{CH}_{3} \mathrm{SSCH}_{3}$ of $\mathbf{1 3}^{+}$and its deuterium-labeled derivatives $13 a^{+}$and $13 b^{+}$followed by reionization with $\mathrm{O}_{2}$ results in substantial decomposition of the intermediate hypervalent radicals (Figure 1). Three series of fragments are recognized from the
NR spectra. First, very abundant hydrocarbon fragments appear at $m / z 27-29\left(\mathrm{C}_{2} \mathrm{H}_{3-5}\right)$ and $m / z$ 39-41 $\left(\mathrm{C}_{3} \mathrm{H}_{3-5}\right)$ that correspond to dissociation of the heptyl group. The reionized $\mathrm{C}_{7} \mathrm{H}_{15}^{+}$fragment appears as a very small peak at $m / z 99$ (Figure $1 a$ ), whereas the $\mathrm{C}_{7} \mathrm{H}_{13} \mathrm{D}_{2}$ fragment from $13 \mathbf{b}$ is only weakly indicated by its dehydrogenation products at $m / z 98$ and 96 (Figure 1c). Note that deuterium labeling in the dimethylamino group $\left(\mathbf{1 3 a}^{+}\right)$does not result in significant mass shifts of the $\mathrm{C}_{2} \mathrm{H}_{3-5}^{+}$and $\mathrm{C}_{3} \mathrm{H}_{3-5}^{+}$ions (Figure 1b), whereas labeling at $\mathrm{C}-1\left(\mathbf{1 3 b}^{+}\right)$causes mass shifts in the $\mathrm{C}_{3} \mathrm{H}_{3-5}^{+}$ion group (Figure 1c). The complementary dimethylamine fragment gives peaks at $m / z 45$ and 44 (Figure 1a) that shift to $m / z 46-48$ in the spectrum of $13 \mathrm{a}^{+}$(Figure $1 \mathrm{~b}$ ). The complementary dimethylamine and hydrocarbon fragments indicate cleavage of the $\mathrm{CH}_{2}-\mathrm{N}$ bond in the intermediate hypervalent radical 13 :

Alternatively, the ions in Figure 1 could arise by reionization of neutral fragments from CAD of $13^{+}$, concurrent with neutralization. However, this appears to be less likely for the following reasons. CAD of $\mathbf{1 3}^{+}$ gives rise to $\mathrm{C}_{7} \mathrm{H}_{15}^{+}$and products of its consecutive dissociations, which, however, do not show losses of highly unsaturated neutral fragments, such as $\mathrm{C}_{2} \mathrm{H}_{3}$, $\mathrm{C}_{3} \mathrm{H}_{3}$, and $\mathrm{C}_{3} \mathrm{H}_{5}$ [48]. By contrast, heptyl radicals undergo extensive dissociations and isomerizations that have moderate activation energies $\left(130 \mathrm{~kJ} \mathrm{~mol}^{-1}\right.$ [49]) and may account for the formation of the $\mathrm{C}_{2} \mathrm{H}_{3-6}$ and $\mathrm{C}_{3} \mathrm{H}_{3-h}$ fragments in the NR spectra (Figure 1). Also noteworthy is the $[m / z 45] /[m / z 44]$ abundance ratio for reionized dimethylamine from $\mathbf{1 3}^{\circ}$ (Figure 1), which is substantially smaller than that obtained for dimethylamine prepared by $\mathrm{He} / \mathrm{CAD}$ of its protonbound dimer (0.91, Nguyen, V. Q.; Tureček, F. unpublished results). This indicates that the dimethylamine molecules are formed by $\mathrm{N}-\mathrm{C}$ bond cleavage from hypervalent 13 and have substantial internal energies to promote further dissociations, which is in keeping with the behavior of other hypervalent ammonium radicals [50].

Second, the NR spectrum of $\mathbf{1 3}^{+}$shows a peak at $m / z 58$ that corresponds to the stable $\mathrm{H}_{2} \mathrm{C}=\mathrm{N}\left(\mathrm{CH}_{3}\right)_{2}^{+}$ immonium ion [41]. The latter shows very clean mass shifts on deuterium labeling, for example, $m / z 58$ to 61 in 13a ${ }^{+}$and $m / z 58$ to 60 in $\mathbf{1 3 b}^{+}$(Figure $1 \mathrm{~b}$ and $c$, respectively). The $\mathrm{H}_{2} \mathrm{C}=\mathrm{N}\left(\mathrm{CH}_{3}\right)_{2}^{+}$ion is the predominant fragment of ion dissociations of $\mathrm{N}, \mathrm{N}$-dimethylaminoheptane; it accounts for $>70 \%$ of the total ion current in the corresponding 70-eV EI mass spectrum (see Experimental and [43]). The $\mathrm{H}_{2} \mathrm{C}=\mathrm{N}\left(\mathrm{CH}_{3}\right)_{2}^{+}$ion thus represents a signature ion for reionized $N, N$ dimethylaminoheptane formed by hydrogen loss from hypervalent 13: The clean mass shifts due to labeling confirm the cleavage of the $\mathrm{N}-\mathrm{H}$ bond in 13:

Third, a cleavage of one of the $\mathrm{N}-\mathrm{CH}_{3}$ bonds in $13^{\circ}$ would yield stable $\mathrm{N}$-methylaminoheptane, which should undergo $\alpha$-cleavage dissociation upon reionization to yield a stable $\mathrm{CH}_{2}=\mathrm{NHCH}_{3}^{+}$ion at $\mathrm{m} / \mathrm{z} 44$ 
[51]. In 13; the latter fragment is obscured by the isobaric ion from dissociation of reionized dimethylamine [50]. However, the presence of immonium ions due to the dissociation of reionized $\mathrm{N}$-methylaminoheptane is evident from the NR spectrum of $\mathbf{1 3 b} \mathbf{b}^{+}$(Figure $1 \mathrm{c}$ ), which shows a peak at $m / z 46$ due to $\mathrm{CD}_{2}=\mathrm{NHCH}_{3}^{+}$. Loss of $\mathrm{CD}_{3}^{\circ}$ from $13 \mathrm{a}^{\circ}$ is indicated by the presence of $\mathrm{CH}_{2}=\mathrm{NHCH}_{3}^{+}(m / z$ 44) in the NR spectrum of $\mathbf{1 3 a}^{+}$(Figure 1b). The latter ion is not formed by further dissociations of $\mathrm{CH}_{3} \mathrm{NHCD}_{3}^{+\cdot}$ [50] or $\mathrm{CH}_{2}=\mathrm{N}\left(\mathrm{CD}_{3}\right) \mathrm{CH}_{3}^{+}$[41].

The NR spectrum of $13^{+}$indicates that cleavages of all three types of bonds, that is, $\mathrm{CH}_{2}-\mathrm{N}, \mathrm{N}-\mathrm{H}$, and $\mathrm{N}-\mathrm{CH}_{3}$, at the ammonium center occur in the hypervalent radical. Although exact quantification of the branching ratios for these three dissociation pathways is difficult due to unknown reionization efficiencies [50,52], the signature ion relative intensities indicate that the propensity for bond cleavage decreases in the $\mathrm{CH}_{2}-\mathrm{N}>\mathrm{N}-\mathrm{H}>$ $\mathrm{N}-\mathrm{CH}_{3}$ series. This order of reactivity is qualitatively similar to that found for $\left(\mathrm{CH}_{3}\right)_{3} \mathrm{NH}^{\cdot}$ [50], $\mathrm{C}_{6} \mathrm{H}_{5} \mathrm{CH}_{2} \mathrm{~N} \cdot \mathrm{H}\left(\mathrm{CH}_{3}\right)_{2}$ (Shaffer, S. A.; Tureček, F., unpublished), and $\mathrm{C}_{6} \mathrm{H}_{5} \mathrm{CH}_{2} \mathrm{~N} \cdot\left(\mathrm{CH}_{3}\right)_{3}$ [53], which showed propensities for bond cleavages, $\mathrm{N}-\mathrm{H}>$ $\mathrm{N}-\mathrm{CH}_{3}, \quad \mathrm{CH}_{2}-\mathrm{N}>\mathrm{N}-\mathrm{H}>\mathrm{N}-\mathrm{CH}_{3}$, and
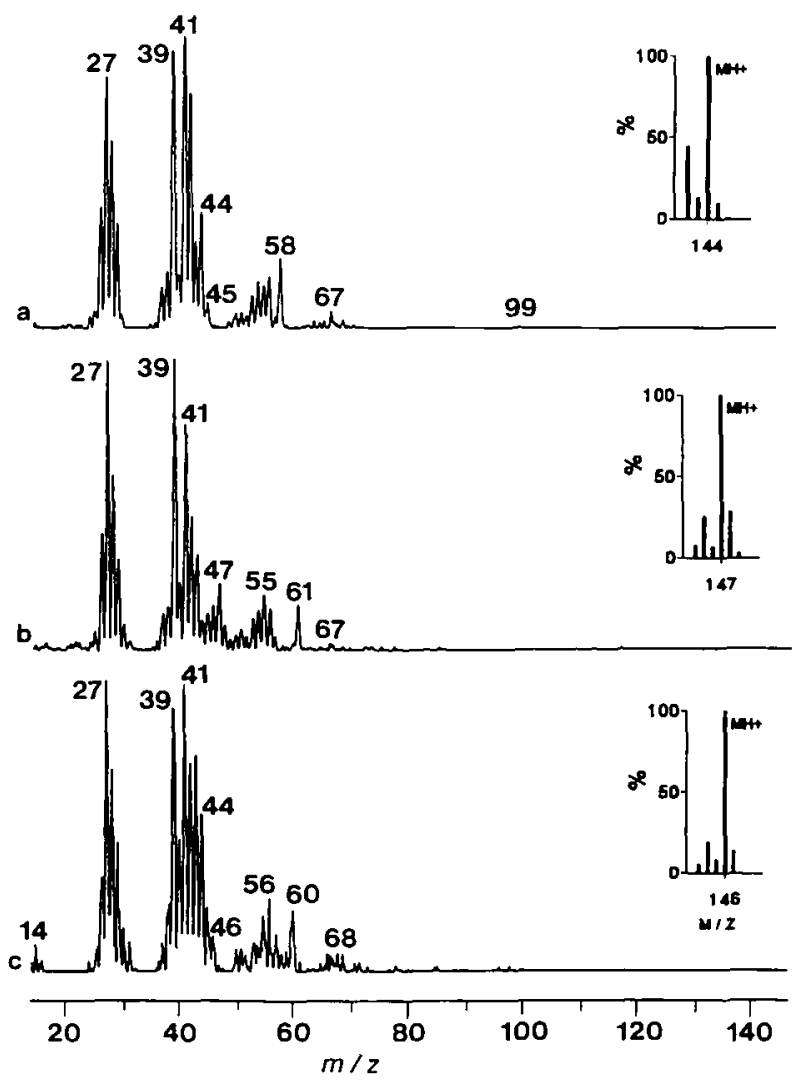

Figure 1. Neutralization-reionization $\left(\mathrm{CH}_{3} \mathrm{SSCH}_{3}, 70 \%\right.$ transmittance $(T) / \mathrm{O}_{2}, 70 \%$ T) mass spectra of (a) $13^{+}$, (b) $13 \mathrm{a}^{+}$, and (c) $13 b^{+}$. Insets show the $[\mathrm{M}+\mathrm{H}]^{+}$region of the isobutane chemical ionization spectrum.
$\mathrm{CH}_{2}-\mathrm{N}>\mathrm{N}-\mathrm{CH}_{3}$, respectively. It should be noted that $\mathrm{N}-\mathrm{C}$ bond cleavages are predicted by theory to be disfavored against $\mathrm{N}-\mathrm{H}$ bond cleavage in the ground electronic states of methyl, dimethyl, and trimethylammonium radicals [35(b), 50]. The facile $\mathrm{CH}_{2}-\mathrm{N}$ bond cleavage in $13^{\prime}$ indicates that extension of the electronic system in the alkyl group has a significant effect on weakening the $\mathrm{C}-\mathrm{N}$ bond through delocalization of the unpaired electron into the diffuse orbitals at the alkyl carbon and hydrogen atoms [35(b), 50].

\section{Bifunctional Ammonium Radicals}

NR mass spectra of ion $9^{+}$were obtained under different $\mathrm{Cl}$ conditions and for neutralization reagents of a range of ionization energies. Previous studies have shown that the stabilities of monofunctional hypervalent radicals depend on the precursor ion internal energy [54], vertical recombination energy of the incipient radical $\left(R_{v}\right)$ [30], and vertical ionization energy $\left(I E_{v}\right)$ of the neutralization gas [28-30]. Ion $9^{+}$was

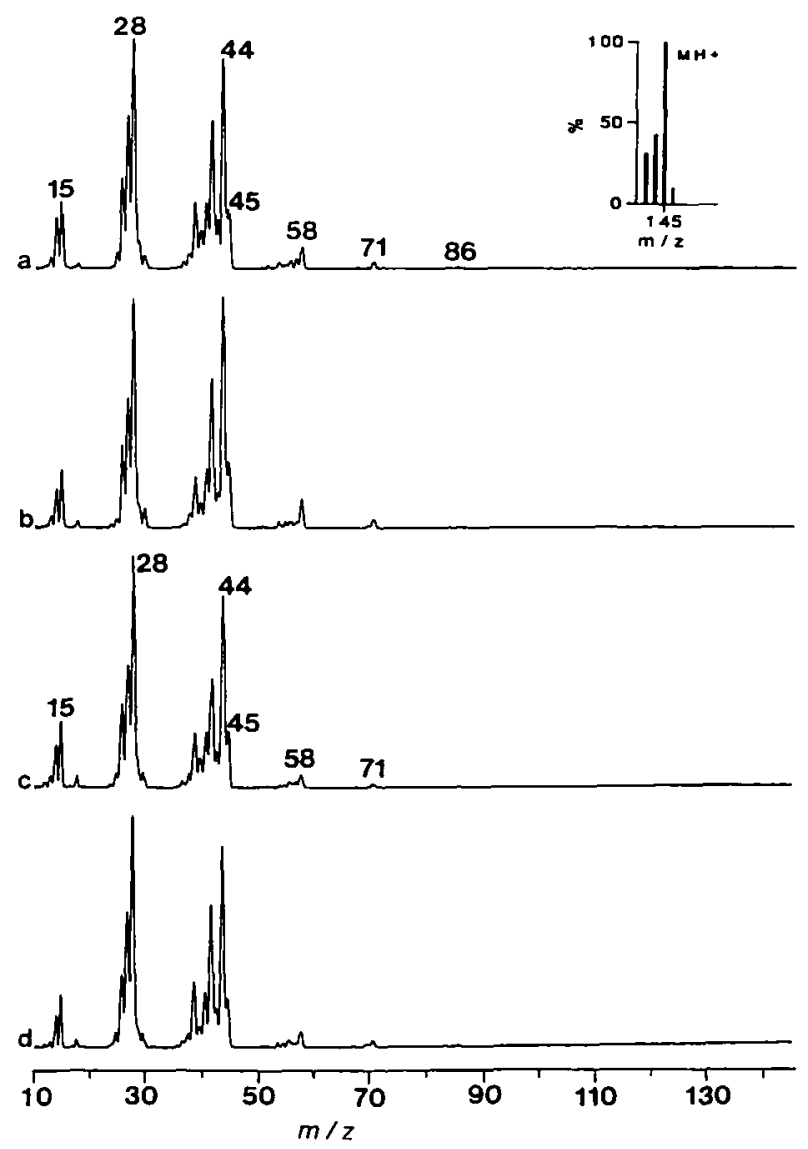

Figure 2. Neutralization-reionization mass spectra of $9^{+}:$(a) Isobutane $\mathrm{CI}, \mathrm{NR}\left(\mathrm{CH}_{3} \mathrm{SSCH}_{3}, 70 \%\right.$ transmittance $\left./ \mathrm{O}_{2}, 70 \% \mathrm{~T}\right)$; (b) isobutane $\mathrm{Cl}$, NR (trimethylamine, $70 \% \mathrm{~T} / \mathrm{O}_{2}, 70 \% \mathrm{~T}$ ); (c) isobutane $\mathrm{CI}, \mathrm{NR}\left(\mathrm{Xe}, 70 \% \mathrm{~T} / \mathrm{O}_{2}, 70 \% \mathrm{~T}\right)$; (d) ammonia $\mathrm{CI}$, $\mathrm{NR}\left(\mathrm{CH}_{3} \mathrm{SSCH}_{3}, 70 \% \mathrm{~T} / \mathrm{O}_{2}, 70 \% \mathrm{~T}\right)$. The inset in (a) shows the $[\mathrm{M}+\mathrm{H}]^{+}$region of the chemical ionization spectrum. 
prepared by exothermic protonation with $\mathrm{C}_{4} \mathrm{H}_{4}^{+}$ $\left(\triangle \mathrm{PA}=227 \mathrm{~kJ} \mathrm{~mol}^{-1}\right)$ by isobutane $\mathrm{Cl}$ and by protonation with $\mathrm{NH}_{+}^{+}\left(\Delta \mathrm{PA}=178 \mathrm{~kJ} \mathrm{~mol}^{-1}\right)$ by ammonia CI. Highly exothermic protonation with $\mathrm{H}_{3} \mathrm{O}^{+}(\Delta \mathrm{PA}$ $=339 \mathrm{~kJ} \mathrm{~mol}^{-1}$ ) by using water $\mathrm{CI}$ also was attempted, but the stable $9^{+}$cations obtained were found to originate from self-CI of 3 , as confirmed by $\mathrm{D}_{2} \mathrm{O} \mathrm{Cl}$, which gave $9^{+}$with no deuterium incorporation. Fast dissociation of $\mathrm{D}_{3} \mathrm{O}^{+}$-deuteronated $9^{+}$could explain this observation. The $\mathrm{C}_{4} \mathrm{H}_{4}^{+}$-protonated cations $9^{+}$were neutralized by collisions with dimethyl disulfide, trimethylamine, and xenon as shown in Figure $2 a-c$, respectively. Electron transfer onto $9^{+}$from all these reagents is substantially endothermic; for the estimated recombination energy of $9^{+}(\sim 3 \mathrm{eV}[50])$, neutralization with dimethyl disulfide ( $\left.\operatorname{IE}_{\mathrm{v}}=8.97 \mathrm{eV}[55]\right)$, trimethylamine (IE $=8.45 \mathrm{eV}[55])$, and $\mathrm{Xe}(\mathrm{IE}=12.13$ $\mathrm{eV}$ [55]) results in energy defects that range from -5.5 to $9 \mathrm{eV}$. The NR spectra obtained with the foregoing reagents, as well as the spectrum obtained by $9^{+}$ formed by ammonia CI (Figure 2d), differ only slightly in appearance and give largely low mass fragments, whereas the reionized $9^{+}$is absent.

One difference in the NR spectra of $9^{+}$is the abundance ratios of $[m / z 45] /[m / z 58]$, which increase with the endothermicity of the electron transfer, for example, $[m / z 45] /[m / z 58]=2.1,2.4$, and 4.2 for neutralizations with trimethylamine, dimethyl disulfide, and xenon, respectively. We attribute the increased formation of $\mathrm{m} / \mathrm{z} 45$ in the latter spectrum to reionization of neutral dimethylamine formed by CAD of ion $9^{+}$(Table 2) concomitant with neutralization. Presumably, the cross section for the highly endothermic electron transfer from xenon decreases relative to that for CAD [52]. Note, however, that CAD remains a minor process, as judged from the absence of reionized

\begin{tabular}{|c|c|c|c|c|c|c|c|c|}
\hline$m / 2$ & 7 & 8 & 9 & $9 a^{\circ}$ & $9 b$ & $10^{\circ}$ & 11 & 12 \\
\hline 173 & & & & & & $\overline{\mathrm{MH}}$ & & \\
\hline 172 & & & & & & $(4.3)$ & & \\
\hline 171 & & & & & & $(0.2)$ & & \\
\hline 158 & & & & & & 0.1 & & \\
\hline 157 & & & & & & 0.6 & & \\
\hline 149 & & & & $\mathrm{MH}^{\circ}$ & & & & \\
\hline 148 & & & & (41) & & & & \\
\hline 147 & & & & (22) & & & & \\
\hline 146 & & & & & $\mathrm{MD}^{\circ}$ & & & \\
\hline 145 & & & $\mathrm{MH}^{\circ}$ & & $(0.4)$ & & & \\
\hline 144 & & & (17) & & & & & \\
\hline 143 & & & (12) & & & & & \\
\hline 134 & & & & 0.5 & & & & \\
\hline 133 & & & & 7.7 & & & & \\
\hline 132 & & & & 0.2 & & & & \\
\hline 131 & & $\mathrm{MH}^{\circ}$ & & & & & & \\
\hline 130 & & $(0.4)$ & 0.6 & & 0.3 & 0.2 & & \\
\hline 129 & & & 8.1 & & & 4.1 & & \\
\hline 128 & & & & & & 30 & & \\
\hline 127 & & & & & & 3.9 & & \\
\hline 126 & & & & & & 1.7 & & \\
\hline 124 & & & & & & 0.1 & & \\
\hline 119 & & & & & & & & $\mathrm{MH}$ \\
\hline 118 & & & & & & & & $(0.7)$ \\
\hline 117 & $\mathrm{MH}^{\circ}$ & & & & & & & \\
\hline 116 & $(0.3)$ & 0.1 & & & & & & \\
\hline 115 & $(0.1)$ & & & & & 0.2 & & \\
\hline 114 & & & & & & 1.8 & & \\
\hline 113 & & 0.2 & & & & 0.1 & & \\
\hline 112 & & & & & & 0.5 & & \\
\hline 106 & & & & 0.3 & & & & \\
\hline 105 & & & & 3.7 & & & & \\
\hline 104 & & & & 64 & & & & \\
\hline 103 & & & & 3.5 & & & & 0.3 \\
\hline 102 & & & 0.1 & 4.5 & 0.3 & & & \\
\hline 70 & 0.8 & 0.8 & 0.5 & 0.1 & 0.4 & & & \\
\hline
\end{tabular}


Table 2. (Comtimmed)

\begin{tabular}{|c|c|c|c|c|c|c|c|c|}
\hline$m / z$ & 7 & 8 & $9^{\prime}$ & $9 a^{\prime}$ & $9 b$ & $10^{4}$ & $11^{\dagger}$ & 12 \\
\hline 101 & 0.1 & & 3.3 & 3.2 & 6.6 & & & \\
\hline 100 & 0.1 & & 27 & 0.3 & 68 & & & \\
\hline 99 & 0.3 & 0.1 & 3.5 & & 0.9 & & & \\
\hline 98 & & & 13 & & 1.1 & 0.4 & & \\
\hline 97 & & & 0.1 & & & 0.2 & & \\
\hline 96 & & & 0.3 & & & 0.1 & & \\
\hline 91 & & & & & & & $\mathrm{MH}^{\circ}$ & \\
\hline 90 & & & & & & & (38) & \\
\hline 88 & & & & 0.3 & & & & 3.7 \\
\hline 87 & & 3.1 & & 0.3 & 0.4 & 0.2 & & 49 \\
\hline 86 & & 31 & 0.4 & & 0.3 & 0.9 & & 0.6 \\
\hline 85 & 0.2 & 18 & 1.1 & & 1.2 & 0.3 & & 0.7 \\
\hline 84 & & 3.5 & 4.1 & & 1.7 & 2.5 & & \\
\hline 83 & 0.1 & 0.1 & 0.4 & & & 0.2 & & \\
\hline 82 & & 0.4 & 0.6 & & & 0.3 & & \\
\hline 81 & & & & & & 0.4 & & \\
\hline 79 & & & & & & 0.1 & & \\
\hline 77 & & & & & & & & 0.3 \\
\hline 76 & & & & 2.1 & & & & \\
\hline 75 & & & & 0.3 & & & 0.3 & \\
\hline 74 & 0.1 & & 0.1 & 2.9 & 0.4 & & 0.2 & 0.6 \\
\hline 73 & 4.3 & 0.2 & 2.3 & 0.3 & 0.6 & 0.1 & & \\
\hline 72 & 61 & 1.6 & 3.4 & 0.8 & 1.1 & 0.5 & & 0.1 \\
\hline 71 & 1.9 & 3.1 & 4.3 & & 1.4 & 1.2 & & 1.0 \\
\hline 70 & 1.2 & 3.6 & 0.8 & & 0.3 & 0.9 & & \\
\hline 69 & 0.1 & 0.2 & 0.1 & & & 0.2 & & \\
\hline 68 & & 0.5 & 0.4 & & & 0.2 & & \\
\hline 67 & & 0.1 & 0.1 & & & 0.1 & & \\
\hline 65 & & 0.7 & & & & & & \\
\hline 61 & & & & 0.3 & & & & \\
\hline 60 & 0.2 & 0.1 & & 2.9 & 2.4 & & 2.4 & \\
\hline 59 & 1.7 & 9.8 & 0.4 & 0.3 & 10 & 1.1 & 68 & 0.3 \\
\hline 58 & 24 & 20 & 12 & & & 24 & 3.7 & 3.9 \\
\hline 57 & 1.7 & 2.4 & 0.8 & & 0.7 & 0.8 & 0.2 & 0.6 \\
\hline 56 & 1.7 & & 1.0 & & 0.7 & 0.9 & & 2.2 \\
\hline 55 & 0.5 & 0.4 & 1.0 & & & 2.1 & & 3.9 \\
\hline 54 & 0.3 & 0.3 & 0.1 & & 0.2 & 0.1 & & 0.2 \\
\hline 53 & & & 0.1 & & & 0.2 & & 0.4 \\
\hline 46 & & & & 0.5 & & 2.2 & 0.2 & 0.4 \\
\hline 45 & & & 1.8 & 0.3 & & 3.3 & 11 & 22 \\
\hline 44 & & & 2.7 & 0.3 & & 5.2 & 0.3 & 0.3 \\
\hline 43 & & & 0.7 & 0.3 & & 1.1 & 2.1 & 1.1 \\
\hline 42 & & & 2.4 & & & 2.7 & 0.5 & 1.7 \\
\hline 41 & & & 0.6 & & & 1.8 & 0.2 & 2.5 \\
\hline 40 & & & 0.1 & & & 0.1 & & 0.2 \\
\hline 39 & & & 0.3 & & & 0.4 & & 1.2 \\
\hline 33 & & & & & & & 0.6 & 0.5 \\
\hline 31 & & & & & & & 3.9 & \\
\hline 30 & & & 0.3 & & & 0.5 & 0.3 & 0.8 \\
\hline 29 & & & 0.1 & & & 0.4 & 3.6 & \\
\hline 28 & & & 0.3 & & & 0.3 & 1.5 & 0.5 \\
\hline 27 & & & 0.1 & & & 0.2 & 0.6 & \\
\hline 26 & & & & & & & & 0.2 \\
\hline
\end{tabular}

a Values are percent relative to the sum of ion intensities measured as integrated peak areas. $9 \mathbf{b}^{+}$ deuteronated by $\mathrm{ND}_{4}^{+}$. 
$\mathrm{CH}_{+}^{+}$, which is complementary to the abundant ion fragment at $m / z 129$ in the CAD spectrum of $9^{+}$ (Table 2). $\mathrm{CH}_{4}$ gives a substantial survivor ion in its NR spectrum to make it detectable in dissociations of $9^{+}[56,57]$. The absence of $\mathrm{CH}_{+}^{+}$is not due to discrimination against low mass fragments because the other $\mathrm{CH}_{n}^{+}$ions do appear in the NR spectrum. The formation of dimethylamine in NR thus points to cleavage of the $\mathrm{CH}_{2}-\mathrm{N}$ bond and the hydrogen bond in the intermediate radical 9 :

The dissociation pathways for 9 were elucidated with deuterium-labeled ions $9 a^{+}$and $9 b^{+}$. The NR spectrum of $9 \mathbf{a}^{+}$(Figure $3 a$ ) shows a clean mass shift from $m /=58$ to 60 for the immonium ion $\mathrm{CD}_{2}=\mathrm{N}\left(\mathrm{CH}_{3}\right)_{2}^{+}$. The latter is likely to be formed by $\alpha$-cleavage ion dissociation of reionized $3 a^{*}$ ", according to its CAD spectrum (Table 1 ), and by analogy with the EI spectrum of 3 [43]. The presence of $m /=58$ and 60 in the NR spectra may indicate loss of $\mathrm{H}^{\circ}$ atom from hypervalent 9 . However, loss of methyl from $9^{\circ}$ followed by reionization of the $N, N, N^{\prime}$-trimethylbutane-1,4-diamine intermediate (14) is also likely to form $m /=58\left(m / z 60\right.$ from $\left.9 a^{\circ}\right)$ by $\alpha$-cleavage at the other dimethylamino group (Scheme I) [43]. The loss of methyl from $9 \mathrm{a}^{\circ}$ is observed indirectly by the presence of $\mathrm{CD}_{2}=\mathrm{NHCH}_{3}^{+}$at $m / z 46$ (Figure 3a). The latter ion is formed by $\alpha$-cleavage dissociation in reionized 14, by analogy with the abundant dissociations of methylalkylamine cation-radicals on EI [43]. On labeling $\left(9 a^{+}\right)$, the peak at $m /=71$ (Figure 3a) shows a clean shift to $m / z 72$, which indicates retention of one $\alpha$-deuterium atom in the ion formed. The probable mechanism for the latter ion formation through neutral fragmentation followed by reionization is shown in

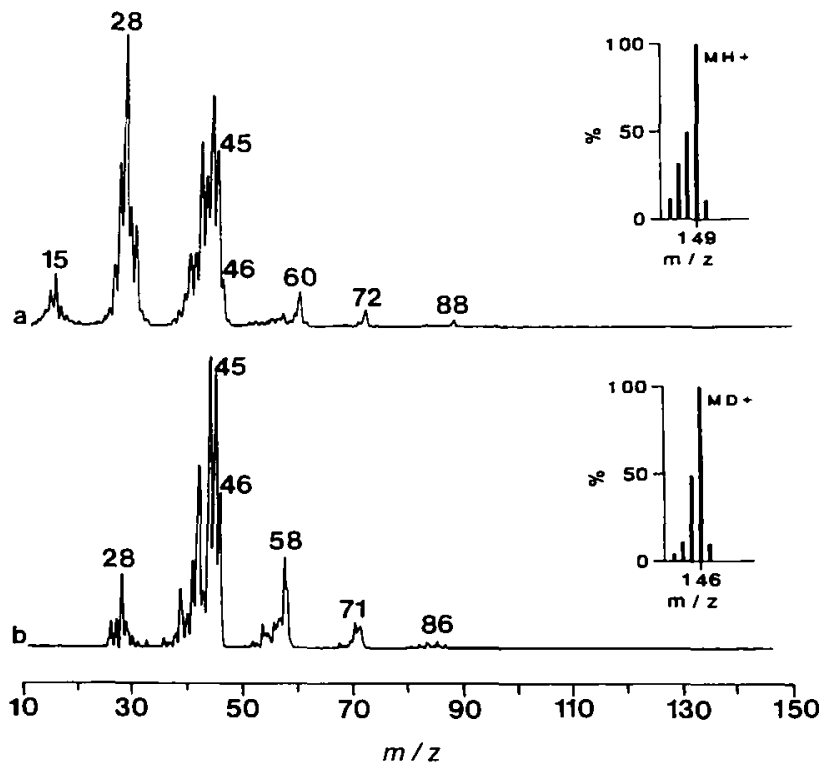

Figure 3. Neutralization-reionization $\left(\mathrm{CH}_{3} \mathrm{SSCH}_{3}, 70 \%\right.$ transmittance $/ \mathrm{O}_{2}, 70 \%$ T) mass spectra of (a) $9 \mathrm{a}^{+}$(isobutane $\mathrm{CI}$ ) and (b) $9 \mathrm{~b}^{+}\left(d_{3}\right.$-ammonia $\left.\mathrm{CI}\right)$. Insets show the $[\mathrm{M}+\mathrm{H}, \mathrm{D}]^{+}$regions of the chemical ionization spectra.

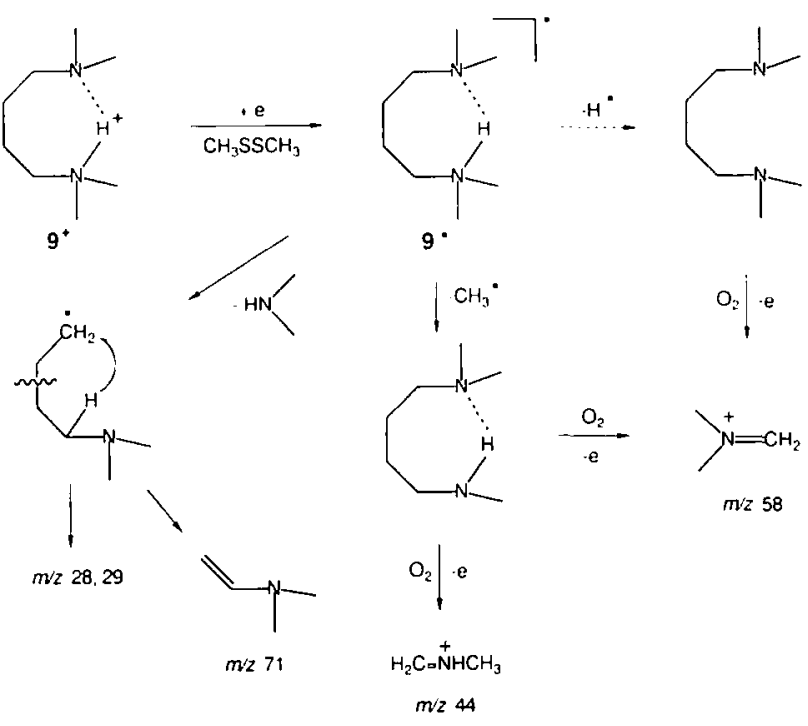

Scheme I

Scheme l. The suggested pathway is supported by the formation of reionized $\mathrm{CH}_{2} \mathrm{CD}_{2}^{+\cdot}$ at $m / z 30$ (Figure $3 a)$. Hence, identification of $\left(\mathrm{CH}_{3}\right)_{2} \mathrm{NH}$, ethylene, and $\mathrm{CH}_{2}=\mathrm{CHN}\left(\mathrm{CH}_{3}\right)_{2}$ and their isotopomers is in line with the $\mathrm{CH}_{2}-\mathrm{N}$ bond cleavage in hypervalent $9^{\circ}$ (Scheme I).

The NR spectrum of $9 \mathbf{b}^{+}$also lacks a survivor ion (Figure $3 b$ ), which indicates that the presence of an $\mathrm{N}-\mathrm{D}$ bond does not increase the kinetic stability of the intermediate hypervalent radical $9 \mathrm{~b}$ : The immonium fragment ion at $m / z 58$ shows no mass shift in the spectrum of $9 b^{+}$, whereas reionized $\left(\mathrm{CH}_{3}\right)_{2} \mathrm{ND}^{+}$ appears at $m / z 46$. Furthermore, the fragment at $m / z$ 86 is in part shifted to $m / z 87$ due to deuterium retention. The formation of the latter ions can be due to loss of methyl from $9 \mathbf{b}$; followed by elimination of the dimethylamino group from reionized $\mathbf{1 4}^{+\cdot}$ (Scheme I). Note that an analogous elimination of $\mathrm{N}\left(\mathrm{CH}_{3}\right)_{2}$ is abundant in ion dissociations of the homologous ion $3^{+\cdot}$ (Table 1$)$.

Unfortunately, the NR spectra of $9^{+}, 9 a^{+}$, and $9 b^{+}$ do not provide unique fragment ions that unambiguously would identify loss of the ammonium hydrogen or deuterium atoms. That the loss of hydrogen atom is a minor dissociation pathway follows from the comparable relative abundances of the immonium ions $\mathrm{CD}_{2}=\mathrm{N}\left(\mathrm{CH}_{3}\right)_{2}^{+}$and $\mathrm{CD}_{2}=\mathrm{NHCH}_{3}^{+}$, which are free of isobaric interferences in the NR spectrum of $9 a^{+}$ (Figure 3a). Ion dissociations of both $N, N, N^{\prime} N^{\prime}$-tetramethyl- and $N, N, N^{\prime}$-trimethylalkane- $\alpha, \omega$-diamine cation-radicals give $\mathrm{CH}_{2}=\mathrm{N}\left(\mathrm{CH}_{3}\right)_{2}^{+}$as the by far predominating product, whereas the $\mathrm{CH}_{2}=\mathrm{NHCH}_{3}^{+}$ from the latter amines is less abundant [43]. Hence, the relatively low intensity of $\mathrm{CH}_{2}=\mathrm{N}\left(\mathrm{CH}_{3}\right)_{2}^{+}$in the NR spectrum of $9^{+}$indicates inefficient formation of 3 by loss of the ammonium hydrogen atom from the hypervalent radical. 
The NR spectrum of $7^{+}$shows extensive dissociation of the intermediate radical 7 and/or the ions formed therefrom on reionization, whereas the survivor ion is absent (Figure $4 b$ ). The signature ion for $7^{+}(m / \Sigma 72$, Table 2$)$ is absent in the NR spectrum, which indicates that no 7 survives the $5.4-\mu$ s flight time between the neutralization and reionization collisions. The peaks at $m / z 45,44$, and in part $m / z 28$ and $15 \mathrm{can}$ be assigned to reionization of neutral dimethylamine [50] formed by $\mathrm{CH}_{2}-\mathrm{N}$ bond dissociation in hypervalent 7 : The other major peaks in the spectrum, $m /=58,42$, and (in part) 15 , originate from $\mathrm{CH}_{2}=\mathrm{N}\left(\mathrm{CH}_{3}\right)_{2}^{+}$[41]. The NR spectrum of $\mathbf{1}^{+\cdot}$ (Figure 4a) also shows $\mathrm{CH}_{2}=\mathrm{N}\left(\mathrm{CH}_{3}\right)_{2}^{+}$as a major fragment, although its subsequent dissociation by elimination of methane $(m / z 42)$ is much less extensive than that in the NR spectrum of $7^{+}$(Figure $4 \mathrm{~b}$ ). Unfortunately, the immonium ion does not distinguish between the possible neutral intermediates, for example, $\mathbf{1}$ and $N, N, N^{\prime}$-trimethylethylenediamine (15), formed by loss of $\mathrm{H}^{\prime}$ and $\mathrm{CH}_{3}$ from 7 ; respectively. The ion dissociations of 1 and $\mathbf{1 5}$ (from 70-eV EI mass spectra) are very similar; the only significant difference is the formation of $\mathrm{CH}_{2}=\mathrm{NHCH}_{3}^{+}(20 \%)$ from 15 [43]. However, in the NR spectrum of $7^{+}$(Figure $4 \mathrm{~b}$ ) the latter fragment is obscured by the isobaric ion from dissociation of dimethylamine. Therefore, it may be concluded safely that hypervalent 7 undergoes $\mathrm{CH}_{2}-\mathrm{N}$ bond cleav-

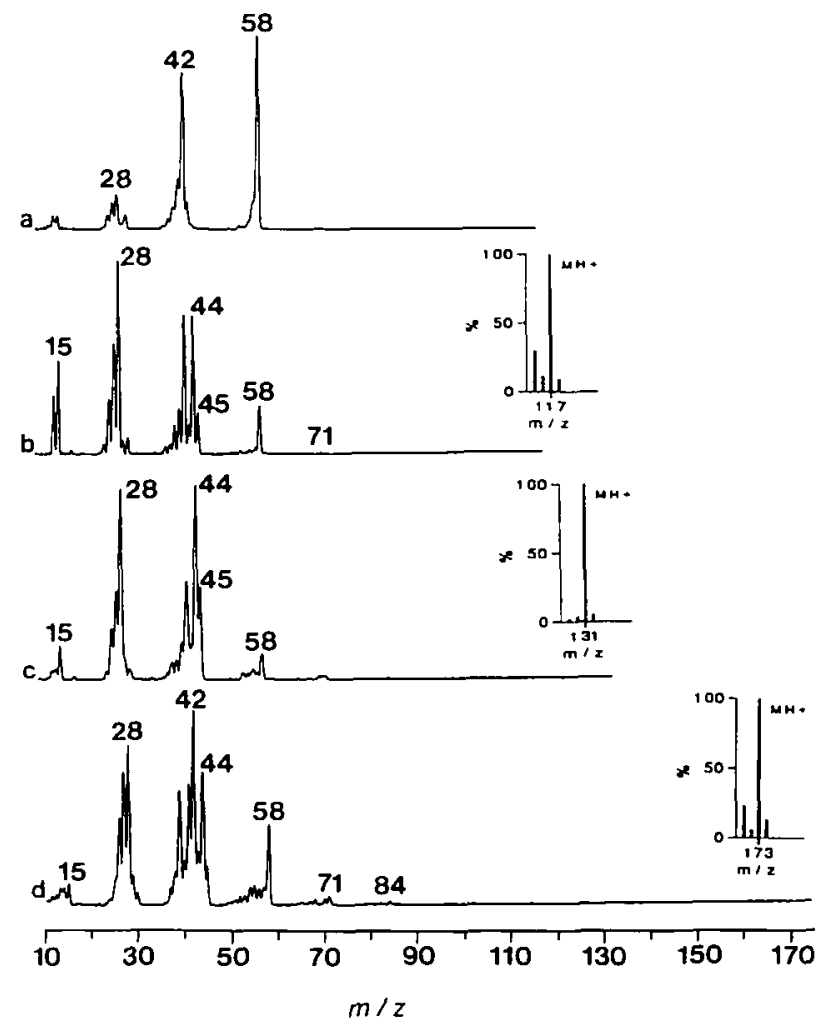

Figure 4. Neutralization-reionization $\left(\mathrm{CH}_{3} \mathrm{SSCH}_{3}, 70 \%\right.$ transmittance $/ \mathrm{O}_{2}, 70 \%$ T) mass spectra of (a) $1^{+}$, (b) $7^{+}$, (c) $8^{+}$, and (d) $10^{+}$. Insets for (b)-(d) show the $[\mathrm{M}+\mathrm{H}]^{+}$regions of the isobutane chemical ionization spectra. age that results in loss of dimethylamine. This fragmentation also breaks the hydrogen bond in neutralized $7^{+}$similar to CAD of the ion (Table 2). The $\mathrm{N}-\mathrm{H}$ and/or $\mathrm{N}-\mathrm{CH}_{3}$ bond cleavages, although unresolved by the present experiments, occur competitively with the loss of dimethylamine.

Neutralization-reionization of $\mathbf{8}^{+}$results in substantial dissociation, such that the peak of the survivor ion $8^{+}$is absent in the spectrum (Figure $4 \mathrm{c}$ ). Note that the absence of the major ion dissociation product of $8^{+}$ $(m / z 85$, Table 2$)$ suggests that radical $8^{\circ}$ dissociates completely before reionization. The spectrum is dominated by the peaks due to reionized dimethylamine $(\mathrm{m} / \mathrm{z} 45,44,28,15)$, whereas $\mathrm{CH}_{2}=\mathrm{N}\left(\mathrm{CH}_{3}\right)_{2}^{+}(\mathrm{m} / \mathrm{z}$ 58 ) and its dissociation products (e.g., $m / z 42$ ) are less abundant. The latter fragments do not distinguish the possible neutral precursors, for example, 2 and $N, N, N^{\prime}$-trimethylpropane-1,3-diamine (16), formed from $8^{\circ}$ by loss of $\mathrm{H}^{\circ}$ and $\mathrm{CH}_{3}{ }^{\prime}$, respectively. The ion dissociations of 2 and $\mathbf{1 6}$ (from 70-eV EI mass spectra) differ only in the formation of $\mathrm{CH}_{2}=\mathrm{NHCH}_{3}^{+}(40 \%)$ from the latter [43]. However, in the NR spectrum of $8^{+}$the $\mathrm{CH}_{2}=\mathrm{NHCH}_{3}^{+}$ion is obscured by the isobaric fragment from reionized dimethylamine. We conclude that neutralization of $\mathbf{8}^{+}$results in major dissociation by cleavage of the $\mathrm{CH}_{2}-\mathrm{N}$ bond with concomitant break of the $\mathrm{N}-\mathrm{H}-\mathrm{N}$ hydrogen bond. The parallel cleavages of $\mathrm{N}-\mathrm{H}$ and/or $\mathrm{N}-\mathrm{CH}_{3}$ bonds occur to a lesser extent, but are unresolved by the product analysis.

The NR spectrum of cation $10^{+}$is qualitatively similar to those of $7^{+}$and $8^{+}$(Figure $4 \mathrm{~d}$ ). One notable difference is the relatively high abundance of the $\mathrm{CH}_{2}=\mathrm{N}\left(\mathrm{CH}_{3}\right)_{2}^{+}$ion $(m / z 58)$ and its dissociation product at $m / z 42$, compared to those of $m / z 45$ and 44 from reionized dimethylamine. This indicates a greater proportion of $\mathrm{H}^{\circ}$ and/or $\mathrm{CH}_{3}$ loss from hypervalent $10^{\circ}$ as opposed to the $\mathrm{CH}_{2}-\mathrm{N}$ bond cleavage found in the other ammonium radicals $7 ; 8$; and 9 . (Figure 4).

\section{Bifunctional Oxonium Radicals}

The NR spectra of protonated diethers $1^{+}$and $12^{+}$ show abundant low mass fragments that attest to extensive dissociation (Figure 5). The NR spectrum of $11^{+}$(Figure 5a) shows peaks at $m / z$ 32, 31, and 29, which are characteristic of reionized methanol [58]. In addition, the peak at $m / z 45$ corresponds to the stable oxenium ion $\mathrm{CH}_{2}=\mathrm{OCH}_{3}^{+}$, which is characteristic of ion dissociations of 1,2-dimethoxyethane (5) and 2methoxyethanol (17), as observed in the corresponding 70-eV EI mass spectra [43]. The NR spectrum shows that $\mathrm{CH}_{2}-\mathrm{O}$ bond cleavage in $11^{\circ}$ competes with losses of $\mathrm{H}^{\circ}$ and $\mathrm{CH}_{3}$; however, the latter two dissociations are unresolved owing to lack of unique fragment ions.

The NR spectrum of $12^{+}$shows a significantly higher proportion of fragments due to $\mathrm{CH}_{2}-\mathrm{O}$ bond cleav- 


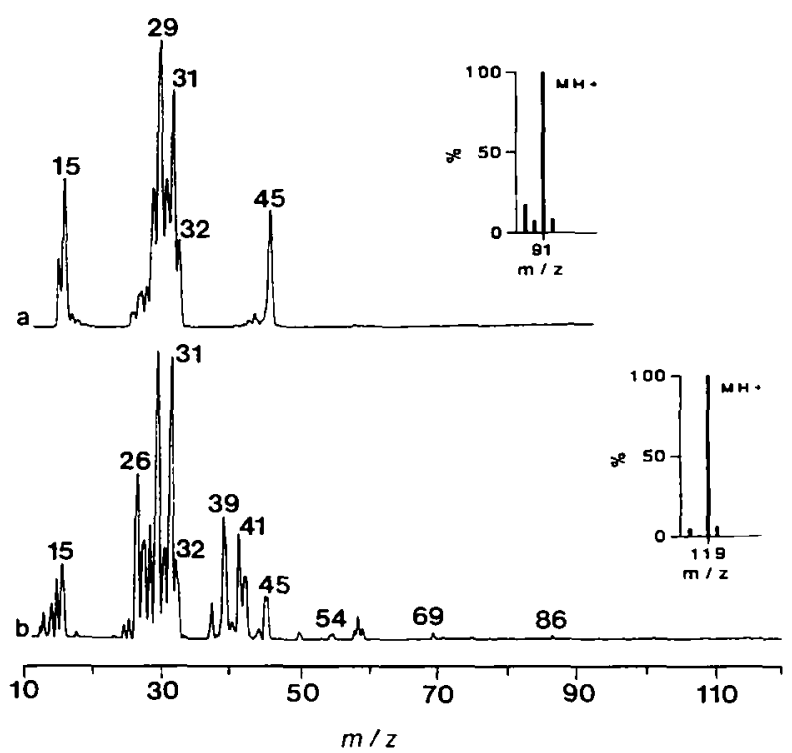

Figure 5. Neutralization-reionization $\left(\mathrm{CH}_{3} \mathrm{SSCH}_{3}, 70\right)^{4}$, transmittance $/ \mathrm{O}_{2}, 70 \%$ T) mass spectra of (a) $11^{\circ}$ and (b) $12^{\circ}$. Insets show the $[\mathrm{M}+\mathrm{H}]^{+}$regions of the isobutane chemical ionization spectrum.

age. This is corroborated by the ions from reionized methanol $(m /=32,31,29)$, as well as hydrocarbon ions from the fragmentation of the connecting alkyl chain, for example, $m /=26,39,41$, and 54 . The NR spectrum also show's peaks at $m /=86,71,69,58$, and 45 . These ions appear in the 70-eV EI mass spectrum of 1,4dimethoxybutane (6) (see Experimental and [43]) and thus represent a signature for the loss of the oxonium hydrogen atom from 11: However, ion dissociations of 4-methoxybutanol (18), a potential product of methyl loss from 11; do not provide unique ions [43] and so the latter dissociation is not firmly identified.

\section{Discussion}

Neutralization of stable hydrogen-bonded ammonium and oxonium cations $7^{-}-12^{+}$results in complete dissociation of the intermediate hypervalent radicals, such that no survivor ions nor products of their ion dissociations are detected. This finding contrasts with the behavior of $\mathrm{NH}_{3} \cdots \mathrm{NH}_{4}$, which showed metastability for both protonated and deuteronated species [36]. A significant difference between the present experiments and those of Porter and co-workers [36] is that the latter authors used alkali metals as neutralization reagents. Collisional electron transfer from $\mathrm{Na}$ or $\mathrm{K}$ to $\mathrm{NH}_{3} \mathrm{NH}_{4}^{+}$was thus carried out close to thermoneutrality due to the small difference between the ammonium recombination energy and the alkali metal ionization energies [36]. By contrast, the present experiments use organic molecules as electron donors, which makes the collisional electron transfer substantially endothermic (vide supra). These conditions typically favor neutral dissociations in NR [30]. To discuss the instability of $7^{\circ}-12$ under NR conditions, the dissociation pathways need to be identified. However, interpretation of the NR data faces several obvious difficulties owing to the instability on reionization of some of the primary dissociation products $(1-6,14-17)$ and their convergent dissociation pathways. With the above caveats in mind we examine the relative intensities in the NR spectra of the structure-significant fragment ions to extract more information on the product formation and hence relative bond stabilities in the hypervalent radicals.

All the hypervalent radicals under study undergo facile cleavage of the $\mathrm{CH}_{2}-\mathrm{X}$ bond $(\mathrm{X}=\mathrm{N}, \mathrm{O})$, which results in elimination of neutral dimethylamine or methanol and formation of the complementary alkyl radicals that carry the other functional group. Interestingly, the methanol molecules are formed from the hypervalent oxonium radicals with excess internal energy. This follows from the comparison of the dissociations of the reionized methanol ions with those produced by neutralization-reionization of stable cation-radicals. For example, the relative intensities of $\left[\mathrm{CH}_{3} \mathrm{OH}^{+\cdot}\right] /\left[\mathrm{CH}_{2} \mathrm{OH}^{+}\right]$from reionization of methanol produced from hypervalent $11^{\circ}$ and $1^{\circ}(0.38$ and 0.29 , respectively) are substantially smaller than that from $\left(\mathrm{CH}_{3}\right)_{3} \mathrm{~N} / \mathrm{O}_{2} \mathrm{NR}$ of methanol cation-radical, which gives a 1.2 ratio. Note that the loss of $\mathrm{H}^{\circ}$ from $\mathrm{CH}_{3} \mathrm{OH}^{+\cdot}$ requires only $76 \mathrm{~kJ} \mathrm{~mol}{ }^{\prime}$ at the dissociation threshold [59], and thus the $\left[\mathrm{CH}_{3} \mathrm{OH}^{+}\right] /\left[\mathrm{CH}_{2} \mathrm{OH}^{+}\right]$ ratio represents a sensitive probe of the internal energy in reionized $\mathrm{CH}_{3} \mathrm{OH}^{+}$. The dimethylamine molecules that are produced from $7 ; 8 ; 9$, and $10^{\circ}$ and give, after reionization, $\left[\mathrm{C}_{2} \mathrm{H}_{7} \mathrm{~N}^{+}\right] /\left[\mathrm{C}_{2} \mathrm{H}_{6} \mathrm{~N}^{+}\right]=0.31,0.48,0.29$, and 0.31 , respectively, which are to be compared with the same ratio from $\mathrm{CH}_{3} \mathrm{SSCH}_{3} / \mathrm{O}_{2} \mathrm{NR}$ of $\left(\mathrm{CH}_{3}\right)_{2} \mathrm{NH}^{+}$, which gives 0.37 . Note that the endothermicity $\Delta H_{\mathrm{r}}=137 \mathrm{~kJ} \mathrm{~mol}{ }^{-1}$ for $\left(\mathrm{CH}_{3}\right)_{2} \mathrm{NH}^{+}$. $\rightarrow \mathrm{CH}_{3} \mathrm{NH}=\mathrm{CH}_{2}^{+}+\mathrm{H}^{\cdot}$ is substantially greater than that for the analogous dissociation of $\mathrm{CH}_{3} \mathrm{OH}^{+*}$. The relatively lower extent of dissociation in reionized $\left(\mathrm{CH}_{3}\right)_{2} \mathrm{NH}^{1 \cdot}$ suggests an upper limit of $140 \mathrm{~kJ} \mathrm{~mol}^{-1}$ deposited in the neutral dimethylamine from hypervalent $7-10$. This internal energy presumably originates from exothermic dissociations of the $\mathrm{CH}_{2}-\mathrm{N}$ bonds. Although the pertinent thermochemical data are unavailable for $7^{-}-10$, the analogous $\mathrm{N}-\mathrm{C}$ bond cleavage in $\left(\mathrm{CH}_{3}\right)_{3} \mathrm{NH}^{-}$is $103 \mathrm{~kJ} \mathrm{~mol}^{-1}$ exothermic and overcomes an activation barrier of $>60 \mathrm{~kJ} \mathrm{~mol}^{-1}$, which results in $>160-\mathrm{kJ} \mathrm{mol}^{-1}$ excess energy in the dissociation channel. However, an interesting difference may be noted between the $\mathrm{C}-\mathrm{N}$ bond dissociations in $7{ }^{\circ}-10^{\circ}$ and that in $\left(\mathrm{CH}_{3}\right)_{3} \mathrm{NH}^{\circ}$ [50]. Upon loss of a methyl radical, the latter forms the dimethylamine molecule with a significantly larger internal energy, as estimated from the very extensive dissociation of the reionized dimethylamine, which gives $\left[\mathrm{C}_{2} \mathrm{H}_{7} \mathrm{~N}^{+\cdot}\right] /\left[\mathrm{C}_{2} \mathrm{H}_{6} \mathrm{~N}^{+}\right]=0.06[50]$. This difference between $7^{-}-10^{\circ}$ and $\left(\mathrm{CH}_{3}\right)_{3} \mathrm{NH}^{\circ}$ may be in part due to the degrees-of-freedom effect, because the complementary radicals from $\mathbf{7}^{-} \mathbf{1 0}$ have greater heat capacities 
than the $\mathrm{CH}_{3}$ radical from $\left(\mathrm{CH}_{3}\right)_{3} \mathrm{NH}$ : It also is possible, however, that the $\mathrm{CH}_{2}-\mathrm{N}$ bond cleavage in $7-10$ proceeds with a lower energy barrier than the $\mathrm{CH}_{3}-\mathrm{N}$ bond cleavage in $\left(\mathrm{CH}_{3}\right)_{3} \mathrm{NH}$; which results in a lower excitation of the products. The latter explanation, albeit tentative, is in line with the very facile $\mathrm{CH}_{2}-\mathrm{N}$ bond cleavage in hypervalent $7-10^{\circ}$.

As discussed for $9^{\circ}$ direct hydrogen loss from the hypervalent radical is a minor dissociation channel. This implies an overall strengthening of the $\mathrm{N}-\mathrm{H}$ bond relative to the $\mathrm{N}-\mathrm{C}$ bonds in the bifunctional hypervalent radical. Note that $\mathrm{N}-\mathrm{H}$ bonds dissociate readily in monofunctional ammonium radicals 13 and $\left(\mathrm{CH}_{3}\right)_{3} \mathrm{NH}^{-}[50]$. The effects of hydrogen bonding in $7-10$ are indicated only indirectly by the NR spectra. Undoubtedly, the nature of hydrogen bonding in $7-\mathbf{1 0}$. differs from that in ions $7^{\circ}-10^{\prime}$ and neutral diamines 1-4 and 14-16. In hypervalent radicals the unpaired electron occupies a diffuse orbital that significantly increases the electron density at the hydrogen atom in the electronic ground state of the radical [50]. Because the hydrogen bond chiefly is due to attractive electrostatic interaction between the proton and the donor atom electrons [16], an increase in the electron density at the hydrogen atom should result in a weaker hydrogen bond in the hypervalent radical. On the other hand, the unpaired electron also weakens the $\mathrm{C}-\mathrm{N}$ bonds in hypervalent radicals, as judged by the substantial exothermicity of $\mathrm{C}-\mathrm{N}$ bond cleavages in methylammonium radicals [35(b), 50]. The relative propensities for $\mathrm{C}-\mathrm{N}$ and $\mathrm{H}-\mathrm{N}$ bond cleavages depend on the electronic structure of the hypervalent radical, namely, the level of mixing of the bonding $\mathrm{N}-\mathrm{C}$ and $\mathrm{N}-\mathrm{H}$ o-orbitals with the diffuse orbital that contains the unpaired electron [50].

Effects of ring size on hydrogen bonding in $7-10^{\circ}$ can be assessed by comparison of the extent of $\mathrm{CH}_{2}-\mathrm{N}$ and $\mathrm{CH}_{3}-\mathrm{N}$ bond dissociations as inferred from the NR spectra. A cleavage of the $\mathrm{CH}_{2}-\mathrm{N}$ bond breaks the ring structure and results in elimination of dimethylamine. A cleavage of the $\mathrm{CH}_{3}-\mathrm{N}$ bond can preserve the ring structure, provided hydrogen bonding is favored in the resulting diamine molecule (Scheme II). These bond cleavages can be roughly assessed from the product ratios, for example,

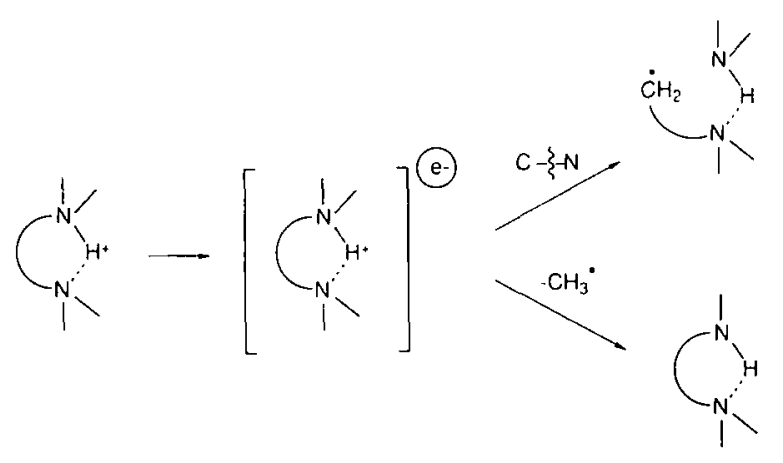

Scheme II $\{[m / z 58]+[m / z 42]\} /\{[m / z 45]+[m / z 44]\}$, where the numerator summarizes ion intensities due to $\mathrm{CH}_{2}=\mathrm{N}\left(\mathrm{CH}_{3}\right)_{2}^{+}$and the denominator those due to dimethylamine. The NR spectra of $7^{+}-10^{+}$give the foregoing products ratios as 1.0, 0.43, 0.62, and 1.7, respectively. This would indicate that ring stabilization through hydrogen bonding is lowest in the six-membered ring of $8^{\circ}$ and increases in larger ring structures. The anomalous value for the five-membered ring in 7 . may be due to a ring strain that promotes the $\mathrm{CH}_{2}-\mathrm{N}$ bond cleavage relative to that of $\mathrm{N}-\mathrm{CH}_{3}$.

\section{Conclusions}

Hypervalent radicals generated by collisional reduction of protonated $\alpha$, $\omega$-diamines and diethers dissociate completely on the microsecond time scale. No substantial stabilization through intramolecular hydrogen bonding of the hypervalent ammonium and oxonium radicals is observed. Subtle effects are found with regard to the propensities for bond cleavage at the hypervalent nitrogen atoms which decrease in the order $\mathrm{CH}_{2}-\mathrm{N}>\mathrm{CH}_{3}-\mathrm{N}>\mathrm{N}-\mathrm{H}$. This differs from the bond cleavage propensities in a monofunctional ammonium radical that show a $\mathrm{CH}_{2}-\mathrm{N}>\mathrm{N}-\mathrm{H}>\mathrm{CH}_{3}-\mathrm{N}$ order. Some stabilization by intramolecular hydrogen bonding in bifunctional hypervalent ammonium radicals is indicated by ring-size effects that appear to favor structures with large rings.

\section{Acknowledgments}

Support by the National Science Foundation (grants CHEM9102442 and CHEM-9412774) and the donors of the Petroleum Research Fund administered by the American Chemical Society is gratefully acknowledged. We thank David Kuhns for the synthesis of 1,4-dimethoxybutane and Viet Q. Nguyen for the NR spectra of dimethylamine.

\section{References}

1. Kollman, P. A.; Allen, L. C. I. Am. Ch'm. Soc. 1970, 92, 6101.

2. Kraemer, W. P.; Diercksen, G. H. F. Chem. Physs. Leth. 1970, 5 , 463.

3. DePaz, N.; Ehrenson, S.; Friedman, L. J. Chem. Plyys. 1970, 52 , 3362.

4. Nagy, P. I.; Dunn, W. J., III; Alagona, G.; Ghio, C. I. Am. Chim. Soc. 1991, 113. 6719 and references therein.

5. Searles, S. K.; Kebarle, P. I. Phys. Chem. 1968, 72, 742.

6. Beauchamp, J. L. Ammu. Re' Phys. Chem. 1971, 22, 527.

7. Morton, T. H.; Beauchamp, J. L. I. Am. Chem. Soc. 1972, 94, 3671.

8. Aue, D. H.; Webb, H. M.; Bowers, M. T. I. Am. Chem. Soc. $1973,95,2699$.

9. Yamdagni, R.; Kebarle, P. I. Am. Ch'm. Sox. 1973, 95. 3504.

10. Aaron, H. S. Top. Sterechem. 1979, 11, 1.

11. (a) Prabhumirashi, L. S.; Jose, C. I. J. Chem. Soc. Furaday Trans. 2. 1975, 71, 1545; (b) Prabhumirashi, L. S.; Jose, C. I. I. Chem. Soc. Faraduy Trans. 2, 1978, 74, 255; (c) Mulla, S. T.; Jose, C. I. 1. Ch'm. Soc. Faraday Trans. 1, 1986, 82, 691; (d) Kelterer, A.-M.; Ramek, M. I. Mol. Struct. 1991, 232, 189. 
12. (a) Caminati, W.; Corbelli, G. 1. Mol. Struct. 1982, 78, 197; (b) Singelenberg, F. A. J.; van der Maas, J. H. J. Mol. Struct. $1991,243,111$

13. McMahon, M. A.; Sharma, S. D.; Curl, R. F., Jr. I. Mol Spectrosi. 1979, 75, 220)

14. Caminati, W.; Fantoni, A. C.; Velino, B. 1. Mol. Struct. 1987, 157. 385

15. Tichy, M. Adt. Org. Ch'm. 1965, 5, 115.

16. Schuster, P.; Zundel, G.; Sandorfy, C. The Hydrosinn Bond; North-Holland: New York, 1976.

17. Bowers, M. T., Ed. Girs Phase lon Chemistry, Vol, 2; Academic Press: New' York, 1979.

18. Schlever, P. v. R.; Williams, I. E.; Blanchard, K. R. I. Am. Chem. Soc. 1970, 92, 2.377.

19. For a review see Tureček, F. In Supplement E: The Chemistry of Hydroxyl, Ether and Peroxide Grouls, Vol. 2; Patai, S., Ed. Wiley: Chichester, 1993; Chap. 8, pF 37.3-403.

20. Morton, T. H. Tetrahtitron 1982, 38, 3195.

21. Audier, H. E.; Milliet, A.; Leblanc, D.; Morton, T. H. I. Am Che'm. Soc. 1992, 11t, 2020.

22. Yates, B. F.; Bouma, W. J.; McLeod, J. K.; Radom, L. I. Chem. Soc. Chem. Commmun. 1987, 204.

23. Ruttink, P. J. A.; Burgers, P. C. Org. Mass Spectrom. 1993, 28. 1087.

24. Cao, J. R.; George, M.; Holmes, J. L.; Sirois, M.; Terlouw, J. K.; Burgers, P. C. J. Am. Chem. Soc. 1992, 174. 2017.

25. Gellene, G. I.; Porter, R. F. Aci. Chem. Re's. 1983, 16, 200.

26. Danis, P. O.; Wesdemiotis, C.; McLafferty, F. W. I. Am. Ch'm. Soc. 1983, 105, 7454.

27. Burgers, P. C.; Holmes, J. L.; Mommers, A. A.; Terlouw, J. K. Che'm. Phys. Lett. 1983, 102, 1

28. Wesdemiotis, C.; McLafferty, F. W. Chem. Rer'. 1987, 87, 485

29. Terlouw, J. K.; Schwarz, H. Angere. Che'm. Int. Ed. Engl. 1987, 26,805 .

30. Holmes, J. L. Mass Spectrom. Ri'i'. 1989, \&, 513.

31. McLafferty, F. W. Science 1990, 247, 925

32. Tureček, F. Org. Mass Spectrom. 1992, 27, 1087.

33. Goldberg, N.; Schwarz, H. Acc. Che'n. Re's. 1994, 27, 347.

34. Perkins, C. W.; Martin, J. C.; Arduengo, A. J.; Lau, W.; Alegria, A.; Kochi, J. K. I. Am. Clum. Soc. 1980, 102, 7753.

35. (a) Kassab, E.; Evleth, E. M. I. Am. Cle'm. Soc. 1987, 109, 1653; (b) Boldyrev, A. I.; Simons, J. 1. Che'm. P/hys. 1992, 97, 6621.

36. Jeon, S.-J.; Raskit, A. B.; Gellene, G. I.; Porter, R. F. I. Am. Chem. Soc. 1985, 107, 4129

37. Lias, S. G.; Bartmess, J. E.; Liebman, J. F.; Holmes, J. L.; Levin, R. D.; Mallard,W. G. J. Phys. Chem. Ref. Datn, Suppl. 1, 1988, 17, 134. For recent revision of the PA scale, see ref 38 .

38. Szulejko, J. E.; McMahon, T. B. I. Am. Chem. Soc. 1993, 115, 7839.

39. Tureček, F.; Gu, M.; Shaffer, S. A. I. Am. Soc. Mass Spectrom. 1992, 3, 493.
40. Drinkwater, D. E.; Turecek, F.; McLafferty, F. W. Org. Mass Spictrom. 1991, 26, 559.

41. Shatfer, S. A.; Turecek, F.; Cerny, R. L. I. Am. Chem. Soc. 1993, $115,12117$.

42. Griller, D.; Lossing, F. P. I. Am. Ch'm. Sox. 1981, 1013, 1586.

43. McLafferty, F. W.; Stauffer, D. B. The Wiley / NBS Reyistry of Mass: Spectral Data. Vol. 1; Wiley: New York, 1989.

4t. Busch, K. L.; Glish, G. L.; McLuckey, S. A. Mass Spectrometry/ Mass Spetrometry: Tedmiques and Applications of Tomdem Mass Spetrometry: VCH Publishers: New York, 1988.

45. (a) Van Koppen, P. A. M.; Illies, A. J.; Liu, S.; Bowers, M. T. Org. Mass Sputrom. 1982, 17, 399; (b) Bass, L. M.; Bowers, M. T. Org. Mass Spettrom. 1982, 17, 229; (c) Proctor, C. J.; McLafferty, F. W. Org. Mass Spectrom. 1983, 18, 193.

46. (a) Ford, G. P.; Herman, P. S. 1. Am. Chem. Soc. 1989, 111 3987; (b) Falvey, D. E.; Cramer, C. J. Tetrahtetron Lett. 1992, 33. 1705 .

47. Reiner, E. J.; Poirier, R. A.; Peterson, M. R.; Csizmadia, I. G.; Harrison, A. G. Can. I. Chem. 1986, 64, 1652.

48. Lavanchy, A.; Houriet, R.; Gaumann, T. Org. Mass Spectrom. $1979,74,79$.

49. Dearden, D. V.; Beauchamp, J. L. I. Phys. Cll'm. 1985, 89, 5359 .

50. Shaffer, S. A.; Tureček, F. I. Am. Chem. Soc. 1994, 116, 8647.

51. McLafferty, F. W.; Tureček, F. Interpretation of Mass Spectra, the ed.; University Science Books: Mill Valley, CA, 1993.

52. Danis, P. O.; Feng, R.; McLafferty, F. W. Anal. Ch'm. 1986, 58. 355.

53. Beranova, S.; Wesdemiotis, C. Int. I. Mass Spectrom. Ion Processes 1994, 13t. 83.

54. (a) Holmes, J. L.; Sirois, M. Org. Mass Spectrom. 1990, 25, 481; (b) Sirois, M.; George, M.; Holmes, J. L. Org. Mass Sprotrom. 1994, 29, 11.

55. (a) Levin, R. D.; Lias, S. G. Ionization and Apprarance Potential Measur'ments 1971-1981; National Bureau of Standards, U.S. Government Printing Office: Washington, DC, 1982; (b) Kimura, K.; Katsumata, S.; Achiba, Y.; Yamazaki, T.; Iwata, S. Handbook of He(l) Photodedron Spectra of Fundamental Organic Molecules; Japan Scientific Societies Press: Tokyo, 1981.

56. Hop, C. E. C. A.; Holmes, J. L.; Wang, M. W.; Radom, L. Ch'm. Plyss. Lett. 1989, 159, 580.

57. Zhang, M.-Y.; McLafferty, F. W. 1. Am. Sor. Mass Spritrom. $1992,3,108$.

58. Wesdemiotis, C.; Fura, A.; McLafferty, F. W. I. Am. Soc. Mass Spectrom. 1991, 2, 459 .

59. Lias, S. G.; Liebman, J. F.; Levin, R. D.; Katafi, S. A. NIST Standard Referenci Database, 19A, Positio lon Energetics, Version 2.01: National Institute of Standards and Technology: Gaithersburg, MD, 1993. 